\title{
Diagnostic Testing in Epilepsy Genetics Clinical Practice
}

\author{
Birute Tumiene, Algirdas Utkus, Vaidutis Kučinskas, \\ Aleš Maver and Borut Peterlin
}

Additional information is available at the end of the chapter

http://dx.doi.org/10.5772/intechopen.69930

\begin{abstract}
Changing landscape of epilepsy genetic testing gives vast opportunities to both patients and clinicians. Significance of precise genetic diagnosis in patients affected by epilepsy cannot be overestimated: it not only gives the opportunities of personalized therapeutical approaches but is also associated with multiple additional benefits for patients, their families, and society. Although the burden of Mendelian and chromosomal diseases amenable to current diagnostic testing measures is unknown, recently, we have comprised a database of more than 880 human genes associated with monogenic diseases involving epilepsy or seizures, EpiGene database (http://www.kimg.eu/en/tools/epigene-database). Besides, more than 50 chromosomal syndromes are related to epilepsy or seizures. Currently, there are no recommendations or guidelines for genetic testing in epilepsy patients addressing specificities of next-generation sequencing technologies. However, as every genetic testing modality has its own characteristics of specificity/sensitivity, range of clinical indications, and possible bioethical and psychosocial implications, genetic testing in epilepsies must be properly selected and applied along with proper clinical genetics/genetic counseling services. In this chapter, an overview of genetic testing modalities and workflows taking into account genetic architecture of epilepsies is given, and practical aspects of genetic testing in epilepsies, including advantages/limitations and clinical utility of tests, are discussed.
\end{abstract}

Keywords: algorithm, diagnostic yield, clinical utility, next-generation sequencing, exome, molecular karyotyping

\section{Introduction}

Recent genetic revolution due to advancements in genomic testing technologies evolves into fundamental changes in clinical practice of not only clinical genetics but also other medical specialties. Changing landscape of epilepsy genetic testing gives vast opportunities 
to both patients and clinicians, however, not without additional challenges. Although the burden of Mendelian and chromosomal diseases, amenable to current diagnostic testing measures, among all patients with epilepsy or seizures is currently unknown, significance of precise genetic diagnosis in patients affected by epilepsy cannot be overestimated: it not only gives the opportunities of personalized therapeutical approaches but is also associated with multiple additional benefits for patients, their families, and society. However, as every genetic testing modality has its own characteristics of specificity/sensitivity, range of clinical indications, and possible bioethical and psychosocial implications, genetic testing in epilepsies must be properly selected and applied along with proper clinical genetics/ genetic counseling services. In this chapter, an overview of genetic testing modalities and workflows taking into account genetic architecture of epilepsies is given, and practical aspects of genetic testing in epilepsies, including advantages/limitations and clinical utility of tests, are discussed.

\section{Diagnostic testing in epilepsy genetics clinical practice ${ }^{1}$}

\subsection{Genetic and clinical heterogeneity of epilepsy}

Both traditional and genomic heritability studies unequivocally show the importance of genetic factors in epilepsy [1, 2]. Genetic factors play a role in more than half of all epilepsies [3]. Although a part of these epilepsies may not be amenable for genetic testing in current clinical practice (e.g., multifactorial or those due to somatic mutations), many monogenic and chromosomal diseases related to epilepsy or seizures may and should be diagnosed. Most of these diagnosable diseases belong to a category of rare diseases (in the European Union defined as a disease affecting less than 1 in 2000). One of the main factors delaying diagnostics of any rare disease is a low index of suspicion [4]. Indeed, for a referral to medical genetic clinic, a neurologist must raise a possibility of a genetic disorder in a patient with epilepsy or seizures first.

In any human disorder with a substantial genetic background, the choice of genetic testing modalities and workflows depends crucially on the genetic and clinical heterogeneity of a given disorder. The overall genetic heterogeneity and number of genetic nosologies involving epilepsy or seizures are largely unknown; however, epilepsy or seizures may be a symptom of many diverse conditions including channelopathies, neurodevelopmental diseases, inborn errors of metabolism, and congenital malformation syndromes [5]. Recently, we have comprised the most extensive to our knowledge database of more than 880 human genes associated with human monogenic diseases involving epilepsy or seizures, EpiGene database (http://www.kimg.eu/en/tools/epigene-database). Besides, more than 50 chromosomal syndromes are related to epilepsy or seizures (see Section 2.5). These numbers give important insights into the huge genetic heterogeneity of human disorders involving epilepsy or seizures, comparable to that of intellectual disabilities [6].

${ }^{1}$ Discussions about usefulness of genetic testing in multifactorial epilepsies (including pharmacogenetic testing) go beyond the scope of this chapter. 
For many years the prevailing "dogma" was that epilepsy is a channelopathy [7], and the first unveiled channelopathy due to mutations in nicotinic acetylcholine receptor gene CHRNA4 became one of long-standing prototypes of genetic epilepsies [8]. Multiple channelopathies presenting with variable phenotypes are currently known (e.g., epileptic encephalopathies (due to mutations in genes HCN1, KCNA2, KCNB1, SCN8A, SLC13A5, STXBP1, and SYN1), benign neonatal seizures (genes KCNQ2 and KCNQ3), a spectrum of generalized epilepsy plus to Dravet syndrome due to SCN1A gene mutations). One of the major targets of current epilepsy genetic research is a group of disorders defined as epileptic encephalopathies; more than 70 genes have been related to this phenotype, explaining $20-25 \%$ of epileptic encephalopathy cases [9]. Relatively, homogenous clinical presentation of this epilepsy phenotype may aid in the recruitment of patients for genetic testing in both clinical setting and research. Distinct group of inherited epilepsies comprises progressive myoclonic epilepsies - an umbrella term for childhood- or adolescence-onset conditions characterized by myoclonus and relentlessly progressive neurodegeneration [10], including Unverricht-Lundborg, Lafora disease, neuronal ceroid lipofuscinoses, type 1 sialidosis, GM2 gangliosidosis, Gaucher disease, MERRF, and some other mitochondrial diseases-and other progressive myoclonic epilepsies due to mutations in genes ASAH1, CERS1, GOSR2, KCNC1, PRICKLE1, PRICKLE2, and SERPINI1. Other epilepsy phenotypes are much more heterogeneous. Surprisingly, the most extensive group of monogenic epilepsies is inherited metabolic diseases, encompassing 373 genes (42\% of all genes) in EpiGene database (discussed more extensively below). The most frequent genetic epilepsy-associated symptoms are psychomotor retardation and intellectual disability (419 and 386 EpiGene diseases, respectively). Indeed, epilepsy is a frequent comorbidity (20-30\% of cases) of syndromic and non-syndromic intellectual disabilities and vice versa; $30 \%$ of patients with epilepsy have intellectual disabilities [11]. Epilepsy or seizure is an accompanying symptom of a vast range of inherited neuromuscular and neurologic diseases, sometimes preceding development of other neurologic symptoms such as spastic paraplegias (SPG6, SPG11, SPG18, SPG35, SPG47, SPG49, SPG50, SPG51, and SPG52), muscular dystrophies (dystroglycanopathies due to mutations in genes B4GAT1, DAG1, FKRP, FKTN, GMPPB, ISPD, LARGE, POMGNT1, POMK, POMT1, and POMT2, congenital megaconial dystrophy (CHKB), merosin-deficient muscular dystrophy (LAMA2)), hereditary ataxias (spastic ataxia 5, ataxia with oculomotor apraxia (APTX), and ataxia-telangiectasia (ATM), spinocerebellar ataxias (SCA) SCA10 (ATXN10), SCA13 (GRM1), SCA15 (KIAA0226), SCA20 (SNX14), SCA17 (TBP), SCA12 (WWOX)), demyelinating diseases (e.g., hypomyelinating leukodystrophy due to mutations in genes AIMP1, FAM126A, GJC2, HSPD1, POLR3A, TUBB4A, leukoencephalopathy with vanishing white matter, megalencephalic leukoencephalopathy with subcortical cysts (HEPACAM, MLC1), adrenoleukodystrophy, metachromatic leukodystrophy, Krabbe disease); and hereditary dystonias (dentatorubropallidoluysian atrophy, dystonia 24 (ANO3), juvenile onset Parkinson disease 19 (DNAJC6), infantile striatonigral degeneration (NUP62)). Paving embryonic neurodevelopmental processes, epilepsy or seizures are very frequent symptoms in syndromes with malformations of cortical development, including megalencephalies (AKT3, EZH2, FGFR3, and PIK3CA), lissencephalies (ARX, RELN, VLDLR, ACTB, ACTG1, DCX, DYNC1H1, KIF2A, LIS1, TUBA1A, TUBB2B, and TUBG1), polymicrogyrias (NDE1, WDR62, FH, KIAA1279, NSDHL, OCLN, GPSM2, RAB3GAP1, RAB3GAP2, RAB18, 
CHD7, and SRPX2), periventricular nodular heterotopia (ARFGEF2) [12], and neurocutaneous syndromes (tuberous sclerosis (TSC1 and TSC2), Sturge-Weber syndrome (GNAQ), incontinentia pigmenti (IKBKG), neurofibromatosis (NF1 and NF2)). However, epilepsy or seizures may also be variably present in multiple other congenital malformation syndromes, including not only CNS malformations (e.g., holoprosencephaly spectrum, pontocerebellar hypoplasia, and corpus callosum agenesis) but also malformations in any other organ. More than 130 congenital malformation syndromes include epilepsy or seizures as phenotypic features (http://www.kimg.eu/en/tools/epigene-database). Five hundred thirty-seven (61\%) of EpiGene disorders are autosomal recessive, 234 (27\%) (autosomal dominant) and 79 (9\%) (X-linked).

It is not credible that any physician would be able to recognize and differentiate about 1000 genetic nosologies involving epilepsy or seizures, especially so that most of them are very rare and/or have just recently been described. Indeed, 228 of 880 EpiGene diseases (26\%) are ultrarare, described just in several patients or families. Moreover, nonspecific and overlapping symptoms are frequent characteristics of these disorders. For many genetic epilepsies, mutations in a single gene may lead to a broad range of possible phenotypes and vice versa; patients with different genetic etiologies may have the same phenotype. To complicate matters still further, characteristic MRI and/or EEG features are very rare pointers or even supporters for a specific genetic etiology [13,14]. Therefore, in clinical practice, genetic evaluation of a patient with epilepsy or seizures is usually not an easy task.

\subsection{Genetic diagnostics of epilepsies: from traditional approach}

Conventional etiological evaluation of epilepsy patients was complex and traditionally included karyotype, molecular karyotyping, and individually tailored serial metabolic and molecular genetic tests [5]. Secondary invasive tests such as biopsies and cerebrospinal fluid examination, aid in diagnosis in a small percentage of additional cases [15]. The main performance characteristic of any genetic testing modality is a diagnostic yield [16]. Clinical utility of various modes of genetic testing was recently evaluated in a retrospective analysis of 110 patients with various epileptic encephalopathies [17]. Genetic causes were identified in $26 \%$ of these patients by applying biochemical genetic testing, array comparative genome hybridization (aCGH), single-gene testing, targeted next-generation sequencing (NGS) testing (gene panels of 38, 70, or 327 genes), and whole-exome sequencing (WES) in six patients. In two patients, diagnosis was made on clinical grounds and not confirmed by genetic testing $(1.8 \%)$, three patients $(2.7 \%)$ had microdeletions revealed by aCGH, eight patients $(7.2 \%)$ had inherited metabolic disorders (IEM), and targeted NGS testing resulted in diagnosis in 14 cases $(12.7 \%)$ of patients [17]. The whole diagnostic pathway leading to the final diagnosis is not analyzed in this publication; however, a comparable pathway in patients with developmental delay/ intellectual disability, many of whom had epilepsy, was described by López-Pisón et al. [18]. In a total of 686 cases (69\% of all cases) in whom etiological diagnosis was not established had 8 tests each on average, including 2887 biochemistry tests, 1582 metabolic tests, 516 karyotyping/subtelomeric deletion tests, and 525 single-gene testing. Indeed, with sequential targeted testing, despite considerable efforts to reach the diagnosis, final diagnosis is frequently not established leading to a long "diagnostic odyssey" arduous for both patients and healthcare 
systems. Moreover, in many clinical situations, traditional approach is not only lengthy but also costly. In a study by Soden et al. before WES or whole-genome sequencing (WGS), patients had an average of 13.3 prior tests for the cost of $\$ 19,100$ per family (seizures were observed in 39 of 100 patients in this study) [19]. The entire traditional diagnostic trajectory average cost was $\$ 16,409$ per patient, substantially higher than the $\$ 3972$ trio-WES cost, in 17 patients investigated by Monroe et al. [20]. The first and the only to date prospective comparison of costeffectiveness of clinical whole-exome sequencing with a usual testing shows even more cost savings: in a cohort of 40 infants with neurodevelopmental disorders and congenital malformations, standard traditional testing had an average cost per diagnosis of US $\$ 21,099$ compared to US $\$ 3937$ for singleton WES. The use of WES early in the diagnostic pathway resulted in more than three times bigger diagnostic yield, while the price of testing was three times smaller [21]. It must be also noted that although Sanger sequencing is frequently entitled as the gold standard in genetic diagnostic accuracy, there are several recent reports about missed variants. In 9/105 families diagnosed through WES, the causative variant has not been detected by previous Sanger testing of a gene [22]. Finally, all the main professional genetic organizations, including the European Society of Human Genetics (ESHG), American College of Medical Genetics and Genomics (ACMG), and Canadian College of Medical Geneticists (CCMG), recognize that NGS testing may be a more practical approach than traditional gene-by-gene testing in certain clinical situations [23-25].

Nevertheless, traditional approach of genetic diagnostics with thorough phenotyping followed by targeted genetic testing can still be of value even in the era of NGS testing. Recently, a retrospective data analysis of 500 unselected consecutive patients coming to a university medical genetic clinic revealed a diagnostic rate of traditional approach reaching $46 \%$. In this study, however, the reason for referral of $31 \%$ of diagnosed (14\% of all) patients was a suspected specific diagnosis or a family history of a definite or suspected genetic disorder (i.e., confirmation or ruling out by a targeted genetic testing was needed only). Importantly, $72 \%$ of the diagnoses were made during the first visits (presumably, due to a highly suggestive phenotype), and further targeted testing resulted in huge expenses [26]. However, in patients with early onset epilepsy and developmental delay, standard clinical evaluation suggested a diagnosis in only $15 \%$ of them (11/71) [27]. Therefore, besides confirmation of the known family mutation, targeted testing is most suitable in cases with distinctive clinical features and minimal locus heterogeneity, for example, MECP2 gene analysis in a girl with characteristic Rett syndrome symptoms and clinical course or 15q11q13 methylation analysis in a patient with presumable Angelman syndrome. Targeted testing may also be important in selected cases where diagnosis cannot be captured by NGS (see Section 2.6). Otherwise, sequential targeted testing is largely inefficient and highly time- and cost-consuming.

\subsection{To genomic testing technologies}

In contrast, next-generation sequencing (NGS) technologies allow for untargeted testing of almost all genomic sequence (whole-genome sequencing (WGS)), almost all coding part of the genome (whole-exome sequencing (WES)), or simultaneous testing of a predetermined set of genes (gene panels). The most comprehensive testing methods-WGS and WESusually allow for the most extensive differential diagnostics; however, extraction of useful 
information from huge amounts of raw data is time- and resource-consuming. Besides, all the bioethical/psychosocial implications pertinent to exhaustive genomic testing technologies must be addressed properly (see Section 2.7). On the other hand, too restrictive diagnostic approach leads to missed diagnoses. In our current era of constant accumulation of knowledge in human genomic health and disease and continuous technological advances of NGS methods, creation of valid recommendations for diagnostic evaluation of human disorders with a considerable genetic background always lags behind scientific and technological achievements and is not an easy task in a constantly changing landscape. Currently, there are no recommendations or guidelines for genetic testing in epilepsy patients addressing specificities of NGS technologies [28].

Although sequencing of the first human genome took 15 years and costs approximately 3 billion US dollars, the new Illumina HiSeq X Ten System can sequence 40-50 genomes per day for approximately 1000 US dollars each [29]. However, amounts of obtained data are overwhelming. Human genome consists of roughly 3.2 billion bp and contains around 3-4 million variants (roughly, 1 out of every 1000 bases) [30]. Certainly, the vast majority of these variants are benign, determining personal particularities of any individual. Exome, the coding part of genome, comprises $1-2 \%$ of the whole-genome sequence ( $65 \mathrm{Mb})$ and contains 30,000-60,000 variants [30,31]. Human genomic variation is almost immeasurable: the most extensive to date human population exome database ExAC (http://exac.broadinstitute.org), encompassing more than 60,000 exomes, contains 7.4 million high-quality variants, a variant in one out of every eight bases on average. More than a half of these variants (54\%) have been found just in one individual each [32].

Besides, extraction of useful information from the huge amounts of WGS/WES data is limited due to our limited knowledge about human genes. As of February 2015, of approximately $\sim 19,000$ protein-coding genes predicted to exist in the human genome, variants that cause Mendelian phenotypes have been identified in 2937 ( 15.5\%), while the genes underlying about half of all known Mendelian phenotypes (i.e., 3152) have not yet been discovered, despite the fact that $\sim 20 \%$ (i.e., 643) have been mapped. Moreover, $\sim 16,063$ other genes still remain candidates for Mendelian phenotypes [33]. Therefore, the major limiting factor of current genomic diagnostics is not data generation, but identification and proper interpretation of causative variants in the whole flood of "genomic noise." Multiple powerful bioinformatic approaches and tools are implemented in WGS/WES data mining; however, technologies cannot totally replace human workload. On the contrary, deep knowledge and extensive skills of multiple professionals are on a higher demand than ever in order to enable successful usage of the technological advances of NGS.

Nevertheless, hundreds of thousands of exomes and tens of thousands of genomes are already sequenced, and projects like 100K Genome Project in UK are well under way [30]. Data on diagnostic rates of WGS in epilepsy patients are limited: WGS revealed pathogenic and likely pathogenic mutations in all six $(100 \%$ yield) patients with severe early onset epilepsy who had previously were refractory to molecular diagnosis by extensive genetic, biochemical, and imaging testing [34]. Other WGS studies mostly include patients with various neurodevelopmental phenotypes; however, considerable part of them have epilepsy or seizures: in 119 children WES resulted in a 33\% and WGS achieved a remarkable 73\% diagnostic rate, while 
cumulative rate of both WES and WGS was 45\% [19]. WES gave a 27\% diagnostic rate $(27 / 100$ patients), while WGS in patients with negative prior WES and aCGH testing resulted in $42 \%$ diagnostic yield (21/50 patients) [35]. Indeed, WGS is the most comprehensive genomic testing mode, encompassing the most extensive mutational spectrum and bypassing many of WES limitations in mutation detection (e.g., reliable identification of deep intronic/regulatory sequence variants or tandem repeats, see Section 2.6). In a recent study of 156 cases with variable phenotypes, an estimated $15 \%$ of causal variants identified by clinical WGS would most likely have been missed by WES [36]. However, our limited knowledge and a huge interpretative workload currently limit the use of WGS, especially in a clinical setting. In the studies mentioned above, the vast majority of data obtained from WGS, especially variants beyond the coding part of human genome, did not have any diagnostic value and could not reliably be ascribed to either benign or pathogenic $[35,36]$.

Meanwhile, WES gets more and more applications in the diagnostic evaluation of patients with epilepsy or seizures. Recently, a study on WES in 314 consecutive patients with unselected epilepsies has shown a diagnostic yield of $38.2 \%$ [37]. WES in 10 sporadic cases of infantile spasms was diagnosed in 40\% [38]. Diagnostic output of WES in neurodevelopmental disorders, including epilepsies, was $41 \%$ in a group of 78 pediatric patients $(12 \%$ of them had epilepsy) [39]. In a cohort of 500 unselected patients coming to a university medical genetic clinic, diagnostic yield of WES was 30\%, while that of patients with epilepsy was 35\% [40]. The output of WES may also depend on when in a diagnostic process it is used: as a first-tier test when a genetically heterogeneous disorder is suspected, as a second-tier after the initial set of tests is normal, or at the end of the whole diagnostic odyssey. In a prospective study of 80 infants with mostly neurodevelopmental disorders and congenital malformations, firsttier singleton WES resulted in $57.5 \%$ diagnostic yield compared to $13.75 \%$ diagnostic yield of standard investigations (including gene panel testing) [41].

Despite the well-recognized benefits of WGS/WES approaches, they also carry with them a high burden of interpretative workload and an increased possibility of detecting incidental findings (see Section 2.6) [42]. According to the current European Society of Human Genetics (ESHG) recommendations, it is preferable to use a targeted approach of gene panels first in order to avoid unsolicited findings or findings that cannot be interpreted [23]. Indeed, about $80 \%$ of human genes are currently not associated with a disease. In the investigation of disorders with limited genetic and phenotypic heterogeneity, gene panels may outperform WES because of better coverage, time- and cost-efficiency, and a focused approach excluding incidental findings [29]. Multiple gene panels exist for the investigation of patients with epileptic encephalopathies, cortical malformations, groups of inborn errors of metabolism, various other clinical indications, and undifferentiated epilepsy phenotypes. However, due to a huge phenotypic and genetic heterogeneity characteristic of disorders involving epilepsy or seizures, as illustrated by EpiGene database (http://www.kimg.eu/en/tools/epigene-database), gene panels may lead to smaller diagnostic yields due to their restrictiveness. Testing of 500 epileptic encephalopathy patients with a gene panel containing 65 genes gave a diagnostic yield of $10 \%$ [43], 30 gene or 90 gene panels in 349 patients with treatment-resistant epilepsies gave a diagnostic yield of 20.3\% [44], a gene panel of 46 genes in 216 patients with various epilepsies gave $23 \%$ diagnostic yield [45], a gene panel trio-testing of 412 genes in 63 probands with variable epilepsies gave $23.8 \%$ diagnostic yield [46], and a combined approach of 46 gene 
panel and targeted exon-level aCGH in 400 patients with early onset epilepsy and developmental delay gave $18 \%$ diagnostic yield [27]. Comparisons of gene panel testing studies are hindered by a huge phenotypic and gene panel variability in all these studies. Indeed, Genetic Testing Registry (http://www.ncbi.nlm.nih.gov/gtr/) database lists more than 60 epilepsy gene panels from several to 377 genes in size (as of 09/04/2016), and the most comprehensive commercially available epilepsy gene panels include from 100 to more than 400 genes, with a proportion of genes associated with epilepsy in animal or association studies only and up to $4 \%$ of included genes currently not related to epilepsy or seizures at all [47]. Moreover, there is a high inconsistency in both gene numbers and compositions of gene panels even though applied for similar groups of patients with epilepsy. In a clinical setting, selection of the most appropriate gene panel in a given patient may be challenging because of overlapping, notfull-blown, atypical clinical presentations [42]. Finally, gene panels rather quickly become outdated because of newly discovered genes [41]. A possible solution to these problems is the use of "virtual" gene panels applied to WES data. Such an approach gives a flexibility in "virtual" gene panel selection and, in cases of negative findings, further possibilities to eventually proceed to a much more untargeted analysis of the whole WES data. Besides, carefully selected and applied to WES sequencing data, "virtual" gene panels can act as a supplementary filtering system aiding in time-efficient and better variant calling in terms of exclusion of both false-positive (by filtering out non-epilepsy-related genes) and false-negative (by inclusion of epilepsy-related genes which could be missed in the whole flood of variants) findings. Recently, we have created a web tool for a customized gene panel creation according to the phenotype (http://www.kimg.eu/generator). Application of this tool to 405 patients with various phenotypes increased diagnostic sensitivity from 25.4 to $29.7 \%$ [42] comparing to the whole WES data analysis.

\subsection{Diagnoses not to miss: treatable inborn errors of metabolism}

Metabolic epilepsies represent an unquestionable area of precision medicine where timely diagnosis and specific treatments tailored to the inherited metabolic defect may markedly improve both the seizures and associated comorbidities as intellectual disability [48]. Regrettably, diagnosis of these and other potentially treatable epilepsy-related diseases is still often delayed [49]. The reasons for that may be insufficient testing due to a low index of suspicion, phenotypic variability and nonspecificity, complexity and limited availability of metabolic testing, and invasiveness of some of the diagnostic methods.

More than 370 inborn errors of metabolism (IEM) can present with epilepsy or seizures, and more than 90 of these disorders have disease-specific treatments leading to a much more better prognosis, improved control of both seizures and comorbid symptoms, and complete avoidance of antiepileptic drugs if diagnosed timely (Table 1; http://www.kimg.eu/en/ tools/epigene-database). However, traditional diagnostics of IEM may be cumbersome as it involves a range of metabolic tests performed in specialized laboratories. Urine and/or plasma specimen are mostly used; however, in some IEM characteristic metabolites can mainly or only be investigated in cerebrospinal fluid (CSF). Histological and/or biochemical investigations of biopsies (e.g., skin, conjunctiva, or muscle) can aid in the diagnostics of certain other IEM. Selection of tests is usually based on a diagnostic hypothesis and requires specialized 


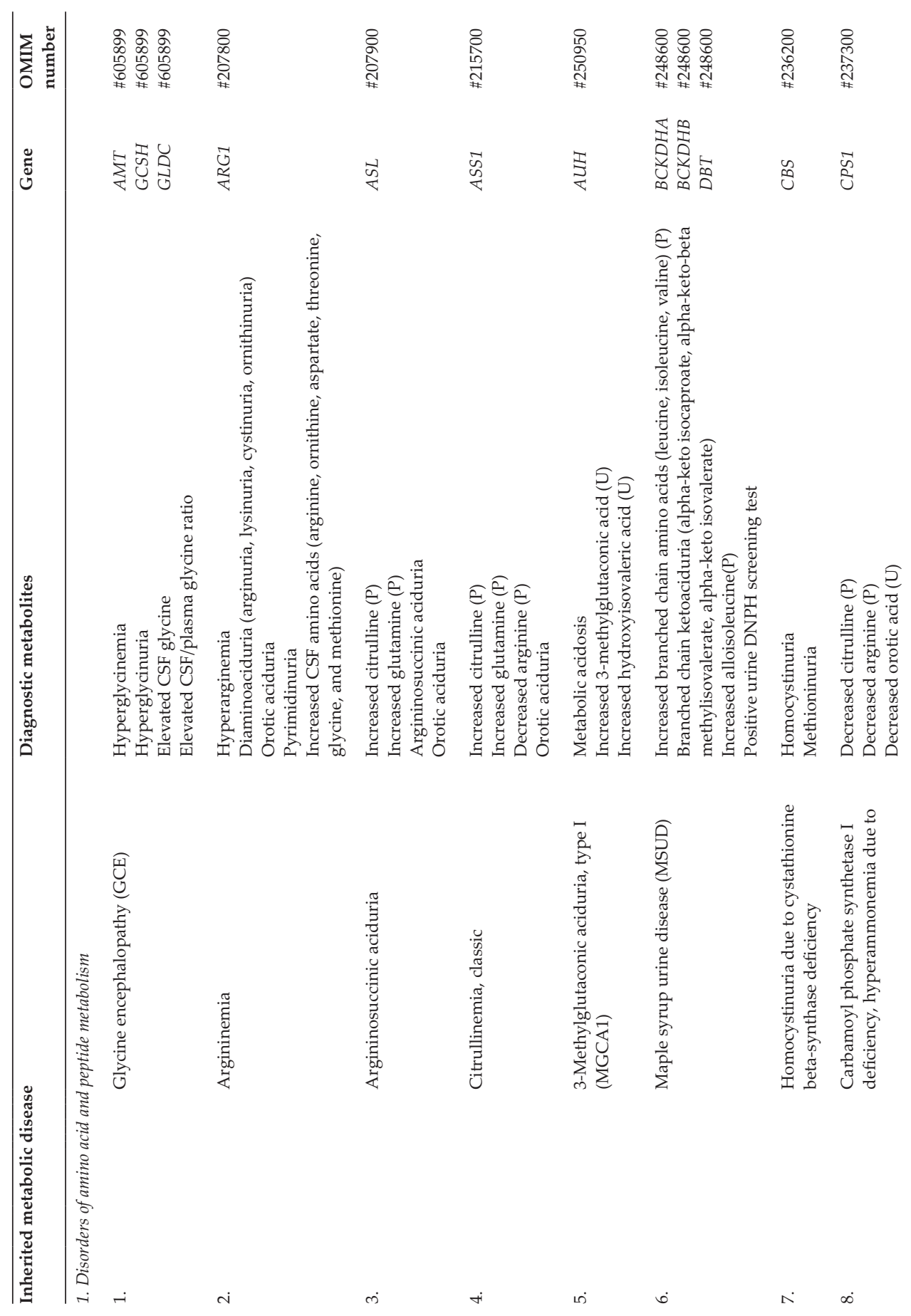




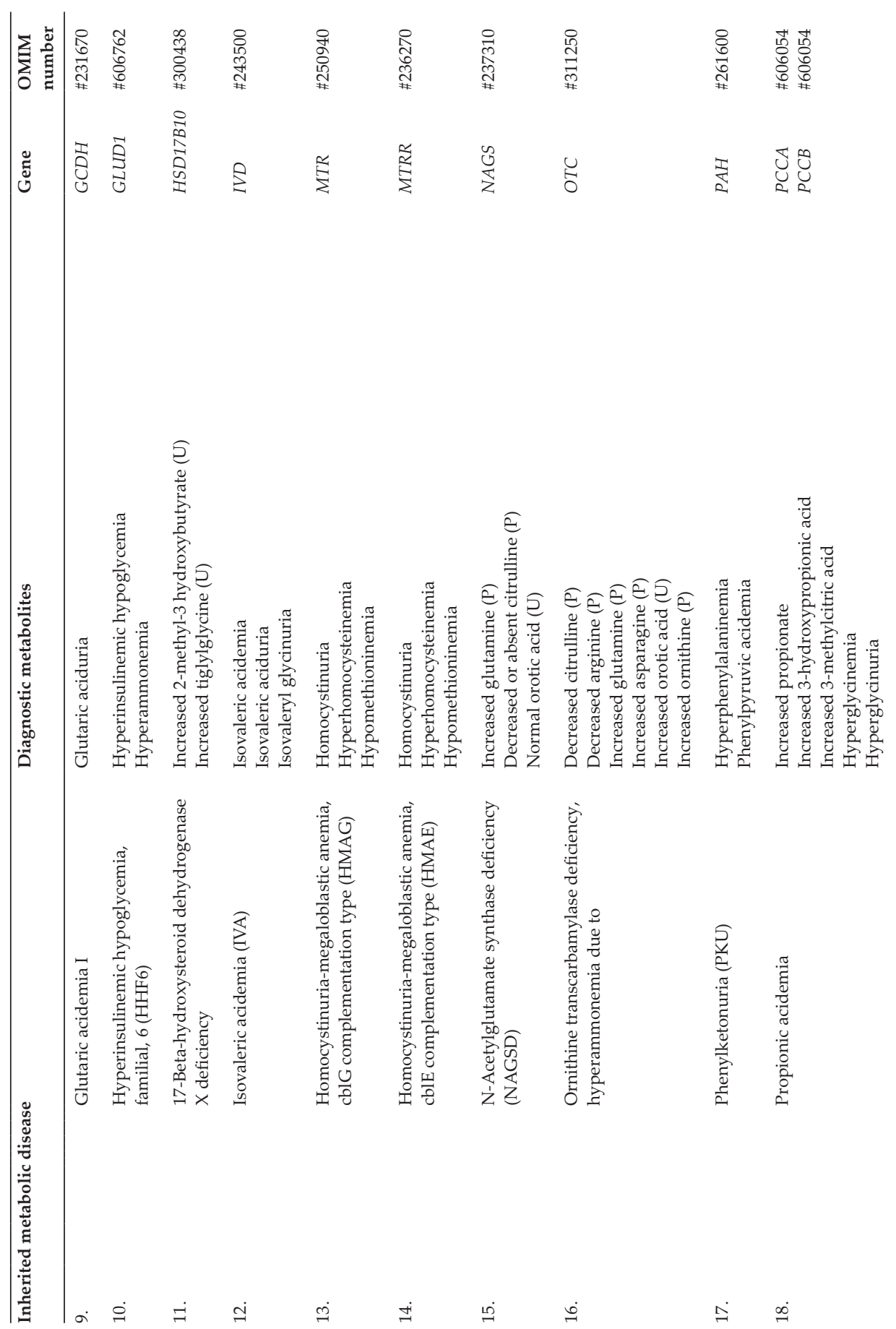




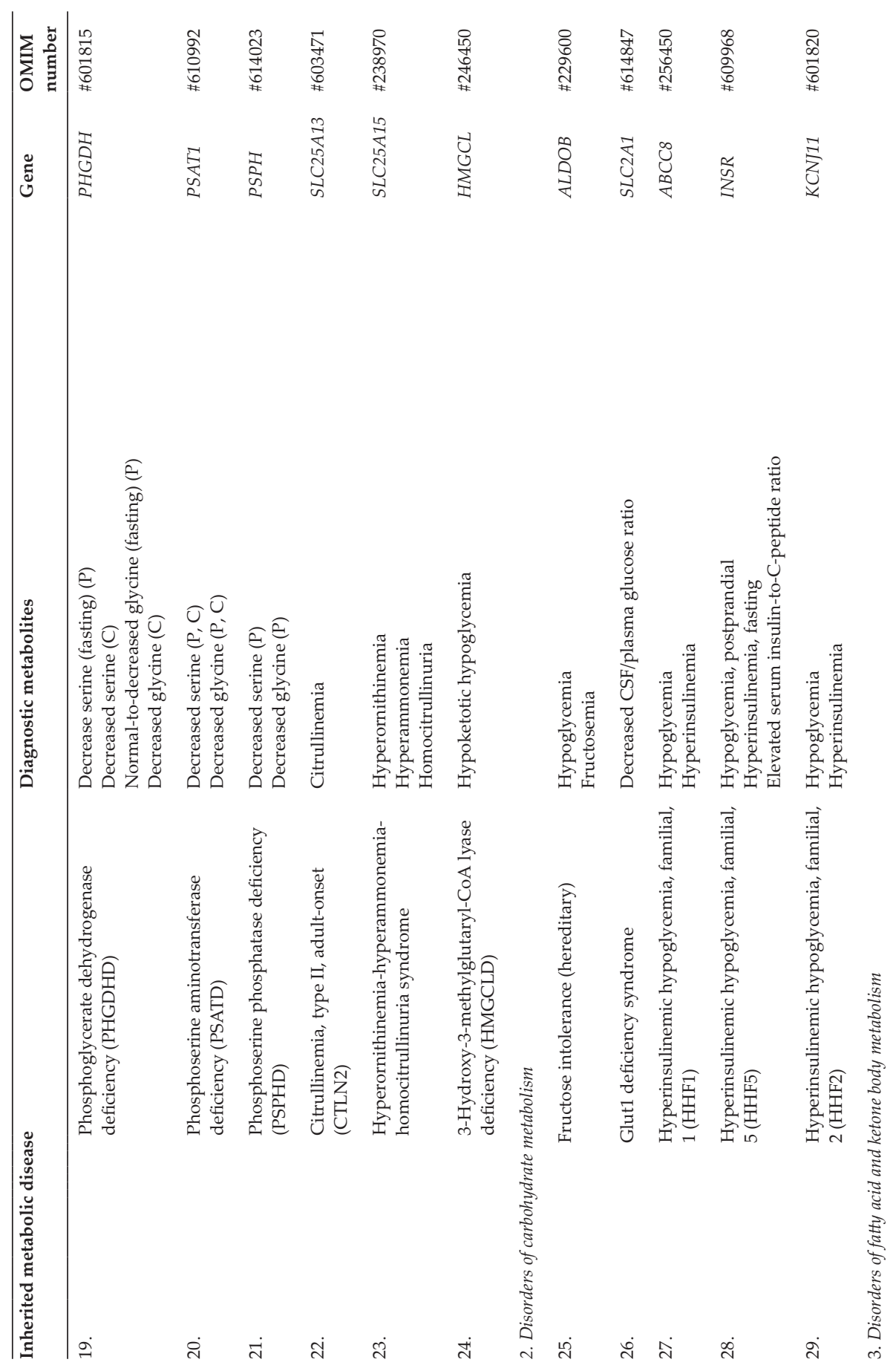




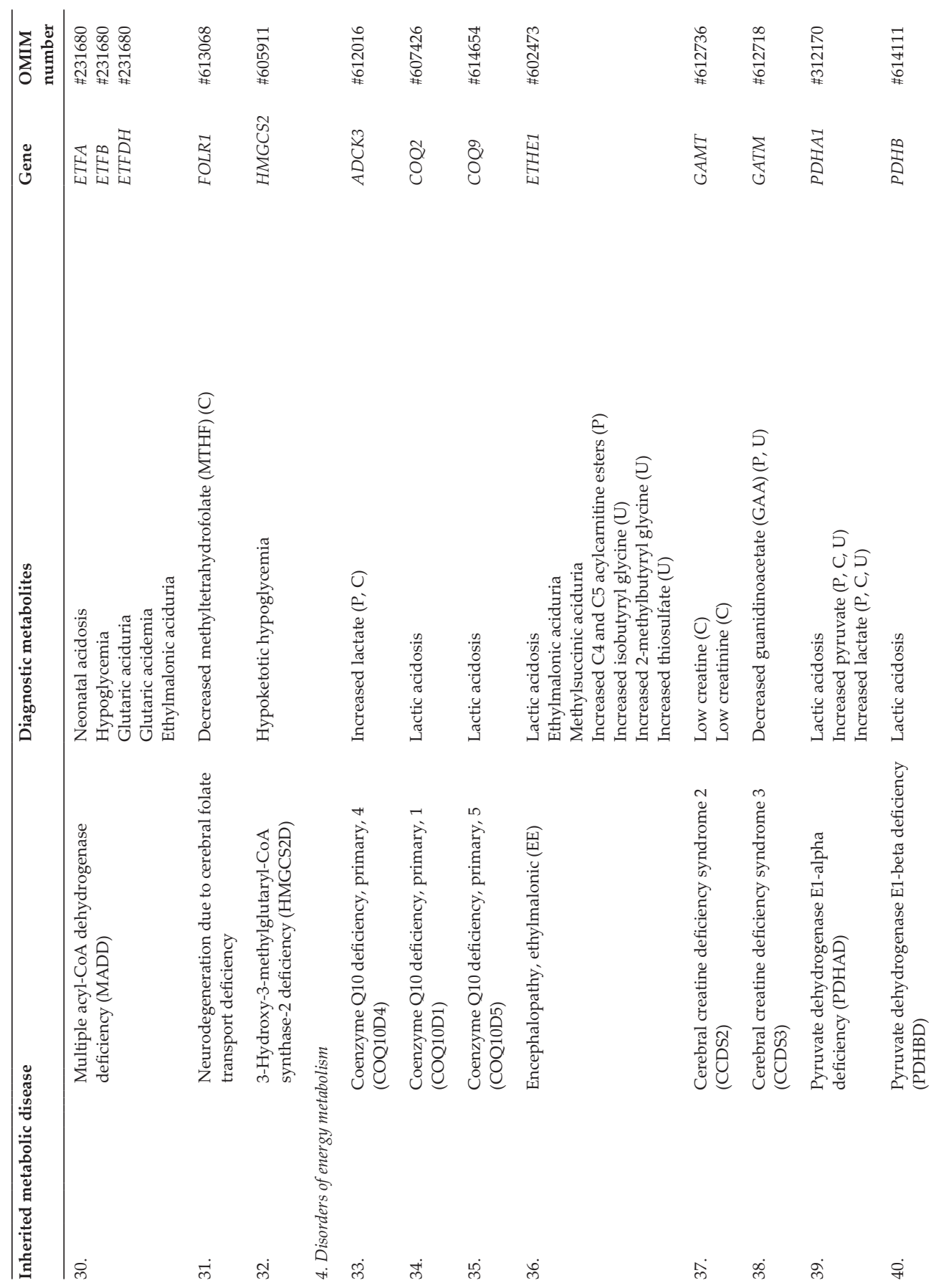




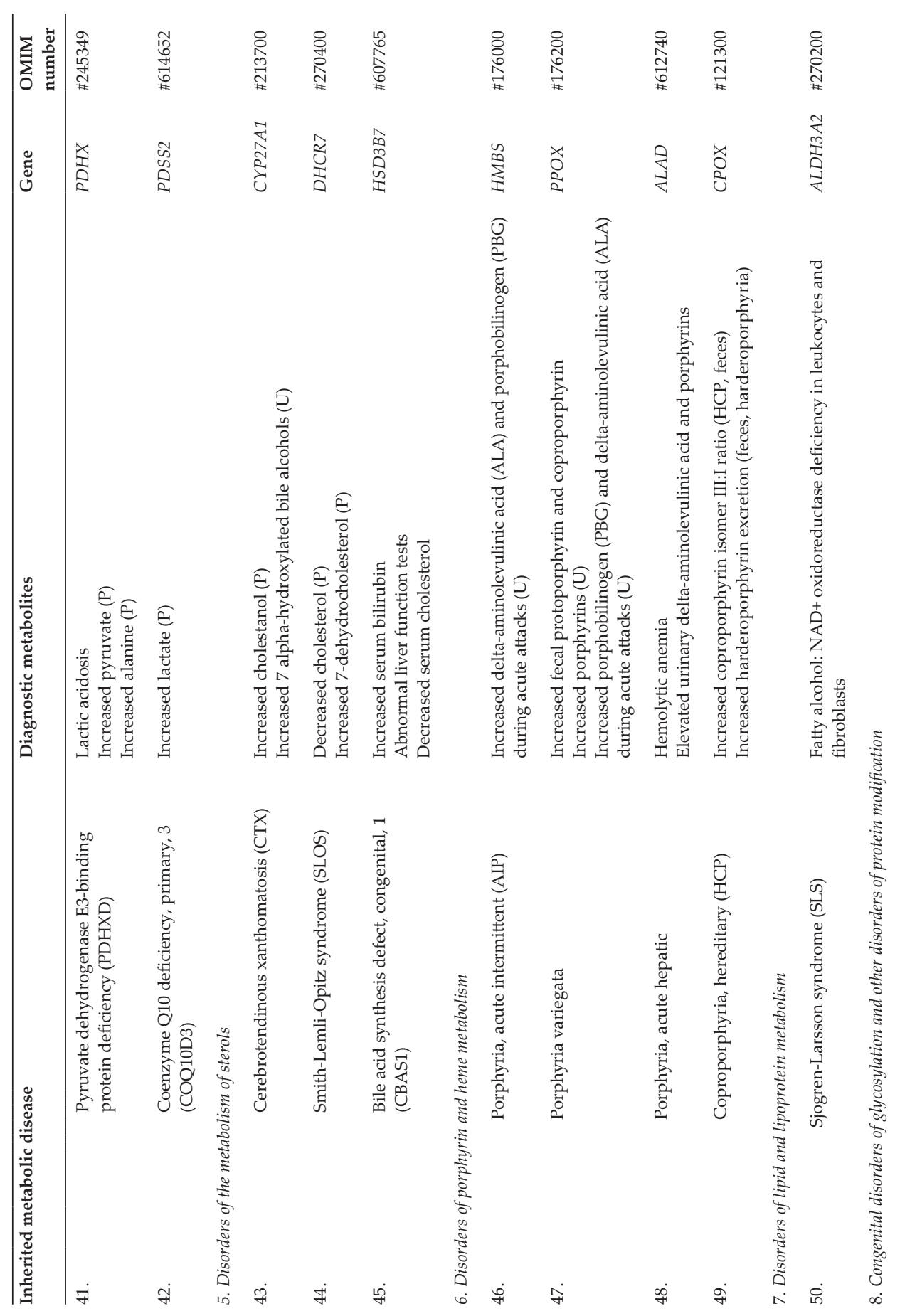




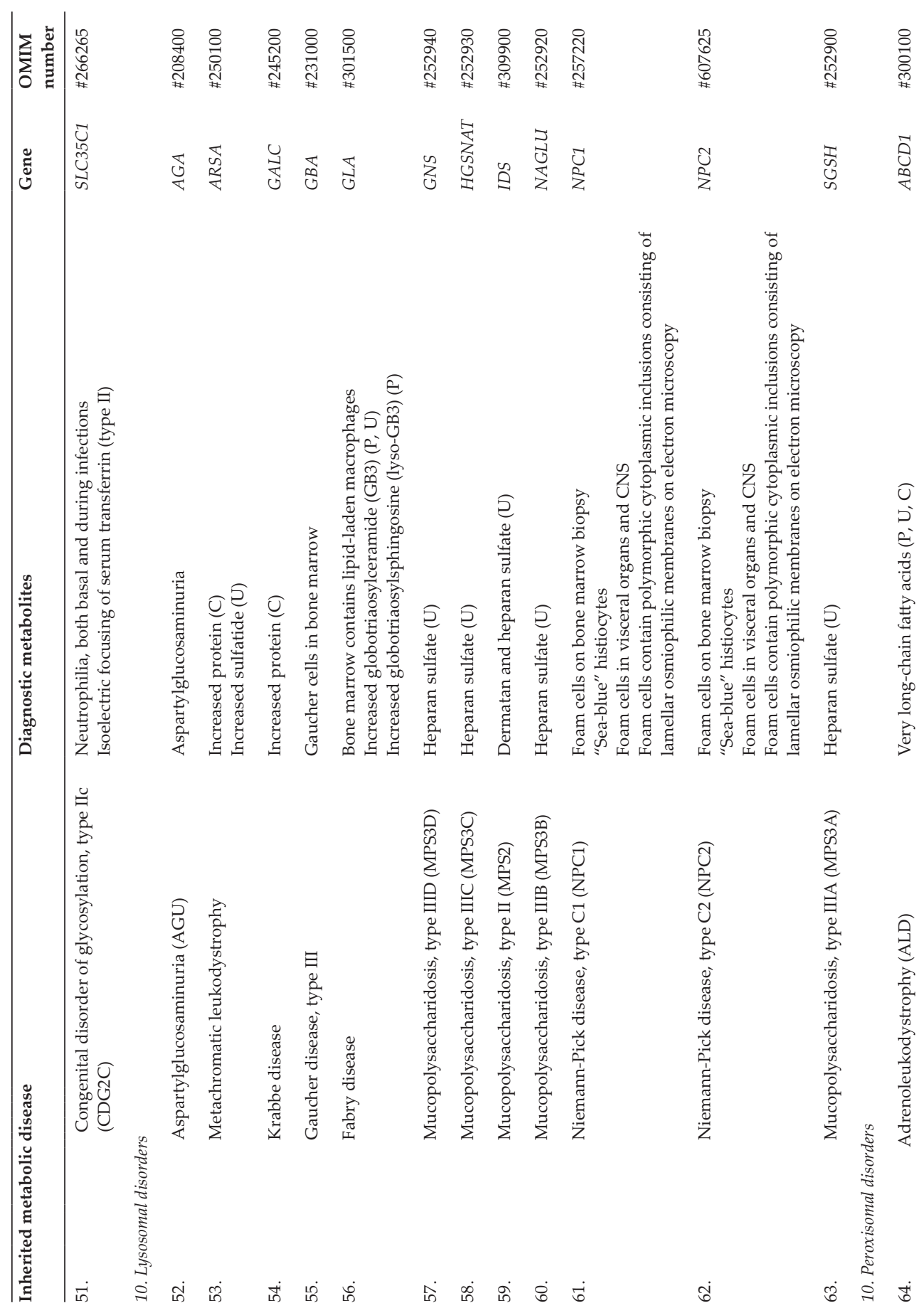




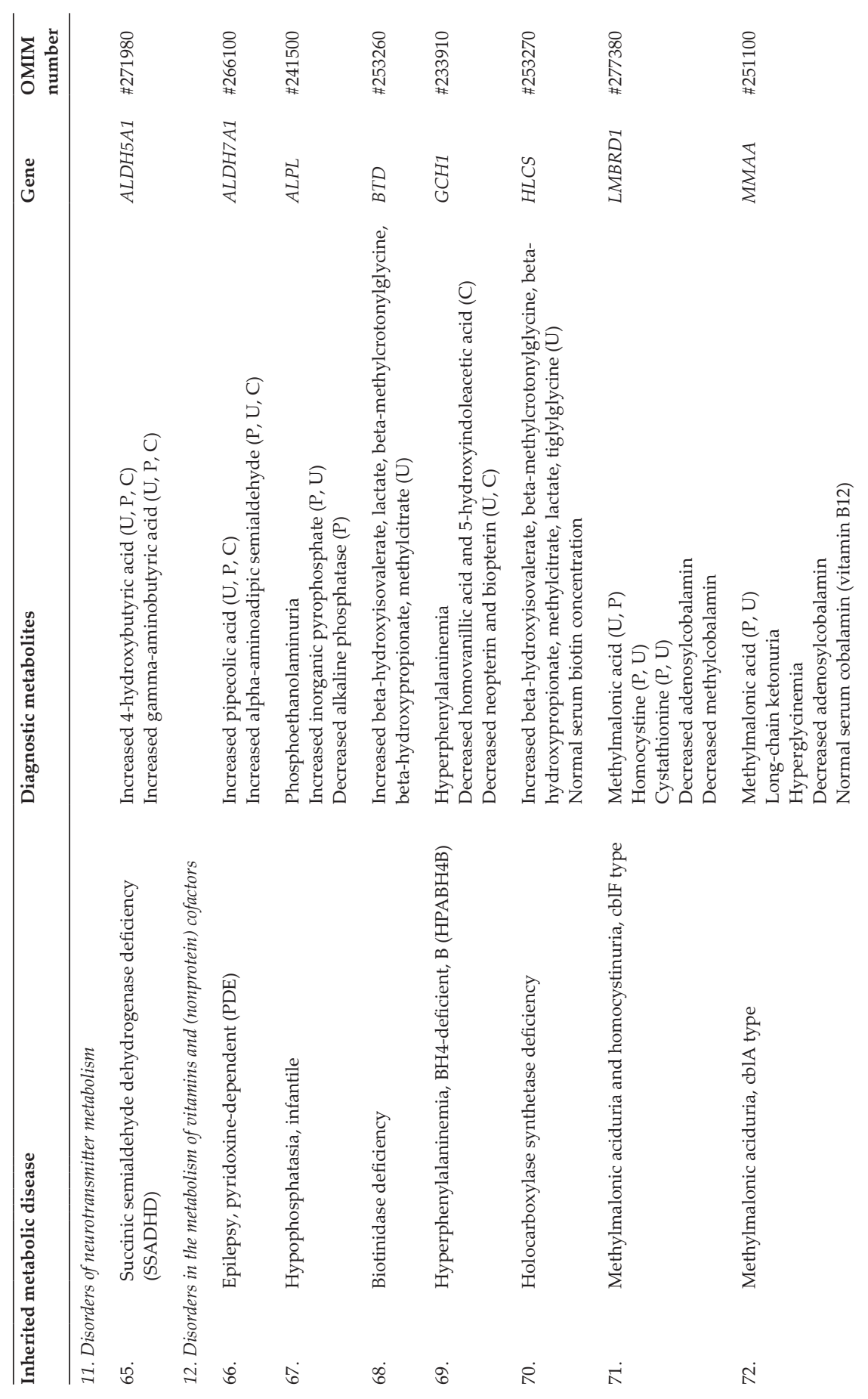




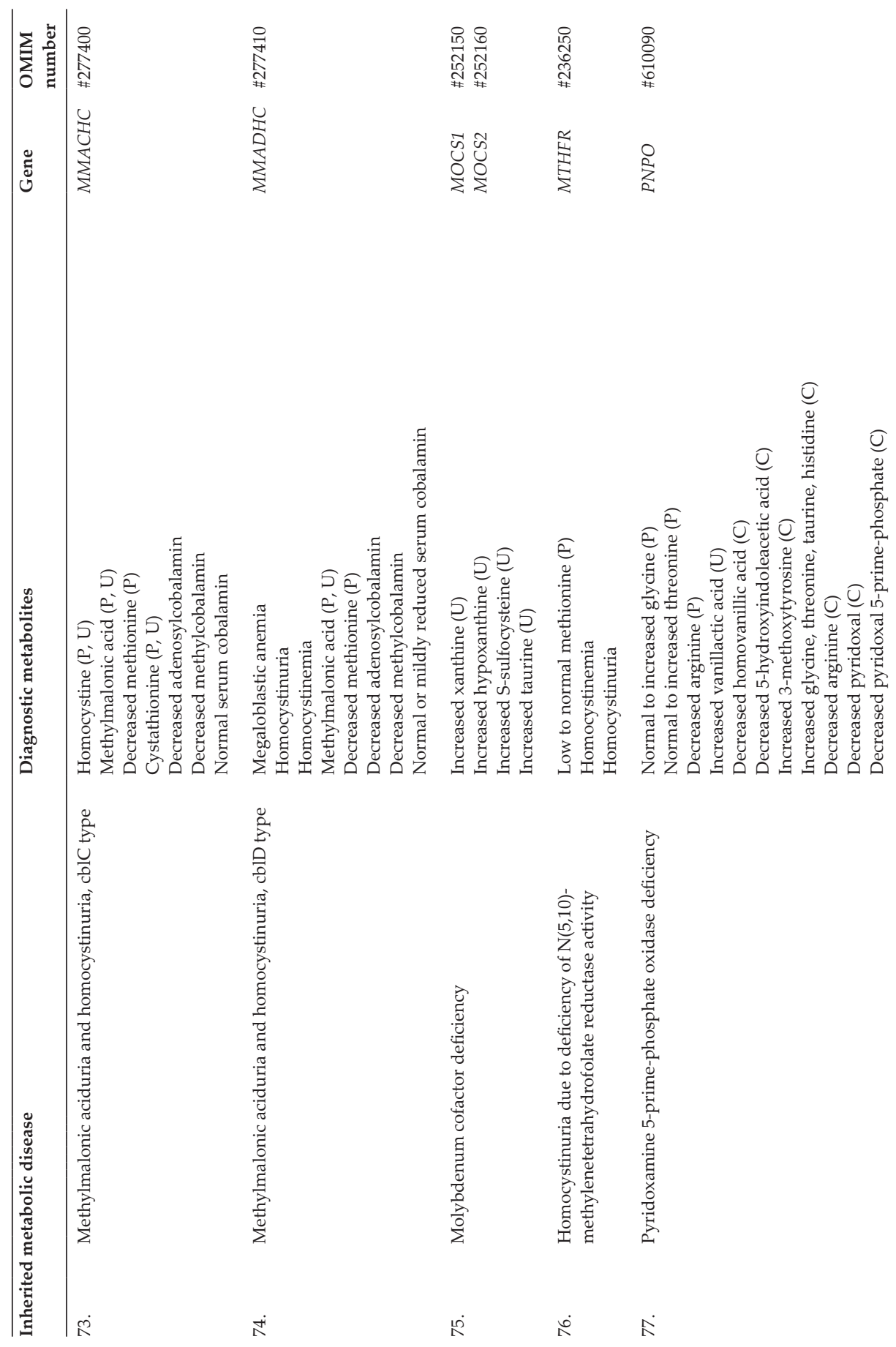




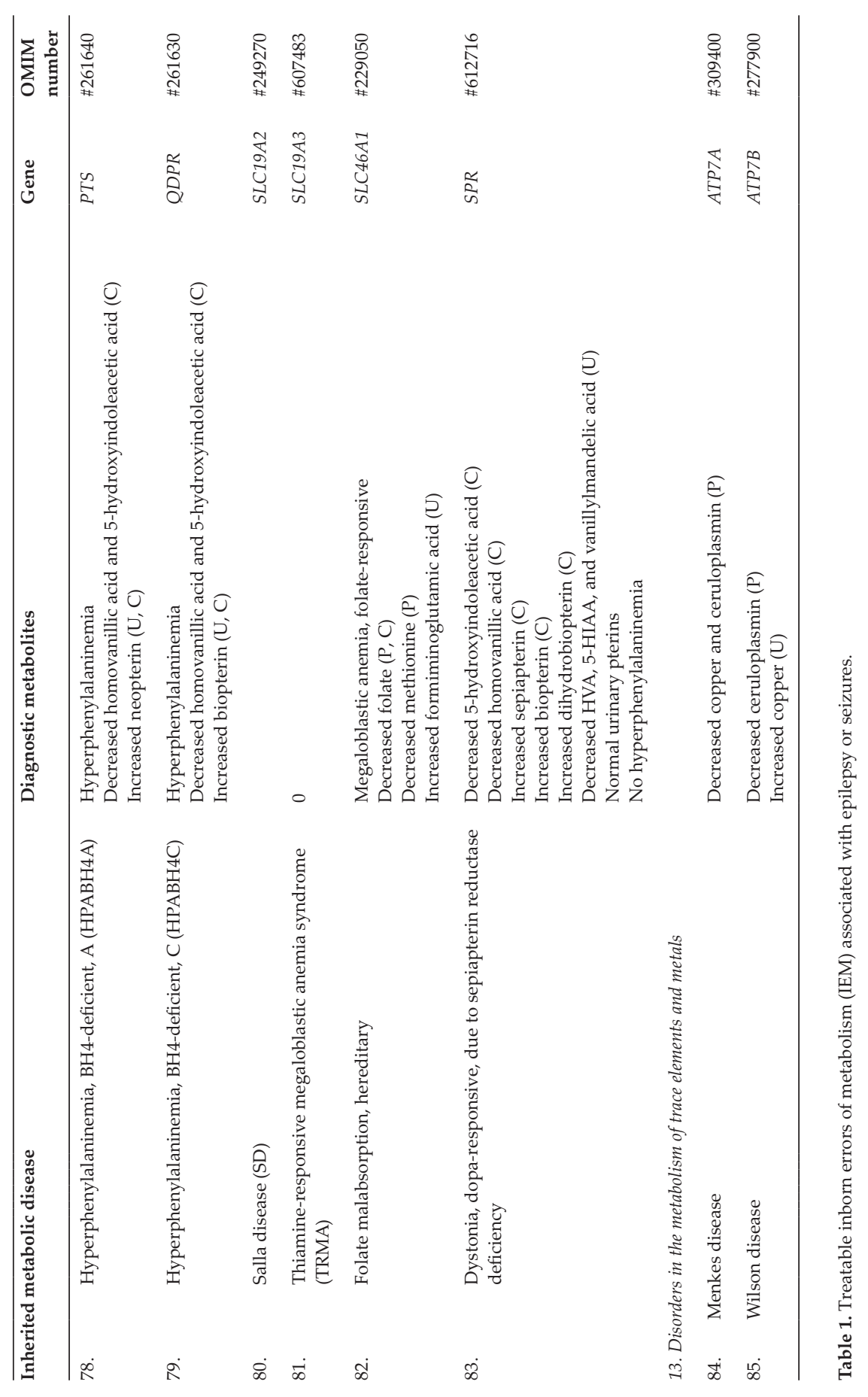


knowledge in IEM. Unfortunately, characteristics of seizure semiology, EEG, or head magnetic resonance imaging/spectroscopy (MRI/MRS) can only seldom guide differential diagnostics of these IEM [13, 48, 50-52]. Besides, there is a huge phenotypic diversity: epilepsy or seizures are usually accompanied by other signs and symptoms; multisystem involvement is common. Seizures can be the main and the first symptom (e.g., in pyridoxine-dependent epilepsy) or a late presentation (e.g., in some of lysosomal storage diseases). Intermediary metabolism defects can present with symptomatic seizures during acute crises only [48, 53]. Consequently, diagnostics of IEM is sophisticated, time-consuming, and sometimes invasive and requires a high degree of specialization, experience, and investments into the diagnostic laboratory equipment and human resources (Table 1).

Molecular genetic tests are usually performed for the confirmation of IEM diagnosis and/ or genetic counseling purposes [52]. However, recent emergence of NGS technologies provides us entirely new diagnostic possibilities. Indeed, previously unsuspected IEM were frequently diagnosed in patients with epilepsy through NGS studies [19, 54], and, vice versa, other genetic diseases were diagnosed in patients with suspected IEM [55]. Noninvasiveness is a further advantage of NGS tests. Therefore, NGS testing might be considered as a primary test and as the most comprehensive screening test for these IEM.

Many IEM present with acute symptoms and metabolic testing in this setting can give the only opportunity for timely diagnosis. However, with ever progressing technological advancements, application of NGS methods can be comparably time-efficient and gives very high diagnostic yield rates. In a study by Soden et al. [19], accelerated whole-genome sequencing has been performed in 15 acutely ill patients in 50 hours (7 of them presented with seizures) with a remarkable diagnostic rate of $73 \%$, while turnaround times of whole-exome sequencing (applied mostly for outpatients) were on average of 16 days. About $20 \%$ of all diagnosed patients (9 patients of 45 diagnosed) were diagnosed with IEM [19].

\subsection{Chromosomal disorders with epilepsy or seizures}

Several hundreds of chromosomal disorders are associated with epilepsy or seizures including aneuploidies (e.g., $10 \%$ of Down syndrome patients have epilepsy), chromosomal rearrangements (e.g., balanced translocations and disrupting known epilepsy-associated genes), and structural variants (syndromic and non-syndromic deletions, duplications, and inversions) [56]. In most of these disorders, epilepsy or seizure is a variable feature, and most of these chromosomal disorders are associated with developmental delay/intellectual disability (DD/ID), autism, and/or congenital malformations (CM). Historically, G-banding karyotype was used for the detection of aneuploidies and large-scale chromosomal rearrangements with an average diagnostic yield in patients with DD/ID and/or CM not exceeding 3\% (excluding Down syndrome; [57]). Fluorescent in situ hybridization (FISH) technique was mostly used for the diagnosis of known, recognizable microdeletion and microduplication syndromes (e.g., 4pdel (Wolf-Hirschhorn), 17pdel (Miller-Dieker), 15q11q13del maternal (Angelman), and 18qdel (de Grouchy), all including seizures), and subtelomeric FISH/subtelomeric MLPA allowed for identification of subtelomeric gains or losses with additional $\sim 3-6 \%$ of diagnoses $[58,59]$. The major breakthroughs came with the advent of microarrays that have evolved from rather crude 
bacterial artificial chromosome (BAC)-based platforms to the contemporary platforms allowing copy number variation (CNV) analysis down to an exon level. These methods increased diagnostic rates in patients with ID/DD and/or CM by 15\% [60] and allowed for elucidation of multiple other microdeletion/microduplication syndromes associated with epilepsy or seizures (Table 2). Besides, NGS approaches for CNV variant calling (e.g., by using depth-ofcoverage analysis-based tool CoNIFER [61] have been developed. Importantly, these methods are restricted to unbalanced chromosomal rearrangements solely; therefore, they do not abolish completely the need for karyotyping. For example, a small part of patients with ring 14

\begin{tabular}{|c|c|}
\hline 1q21.1del/dup & 14q23.3del \\
\hline 1q31.3q41dup & 15q11.2del \\
\hline 1q41q42.12del & 15q13.2q13.3del \\
\hline 1q43q44del & 15q13.3del \\
\hline 2q23.1del/dup & 15q26.1del \\
\hline 2q23.3q24.2del & 15q26.3del \\
\hline 2q24.1del & 16p11.2del/dup \\
\hline 2q24dup & 16p13.11del \\
\hline 2q24.3del/dup & 16p12del \\
\hline 3p25.3del & 16p11.2dup \\
\hline 5p15.31p15.2del & 16q22.1del/dup \\
\hline $5 \mathrm{q} 11.2 \mathrm{del}$ & 17p13.3del \\
\hline 5q14.3q15del & 17p13.1del \\
\hline 6q22.1del & 17p11.2del \\
\hline 6q25.3q27del & 17q11.2del/dup \\
\hline 6q26q27del & 17q21.31del/dup \\
\hline 7q11.23q21.12del & 19p13.2del \\
\hline 7q11.23dup & 20p13del \\
\hline 7q22.2q22.3del & 20q13.33del \\
\hline 8p23.3p23.1del & 21q22del \\
\hline $8 \mathrm{q} 22.2 \mathrm{del}$ & 22q11.2del \\
\hline 9p24.1del & Xp22.33del \\
\hline $9 q 22.3 \mathrm{del}$ & Xp11.4dup \\
\hline 9 q34.3del & Xq11.11del \\
\hline 14q12q22.1del & Xq27q28dup \\
\hline
\end{tabular}

References: 1. Leu et al. [110]; 2. Nevado et al. [111].

Table 2. Microdeletion and microduplication syndromes, associated with epilepsy or seizures. 
and ring 20 chromosomal syndromes do not have any chromosomal material loss [62, 63]. It was estimated that $<1 \%$ of all diagnoses will be undetected by array-based investigations due to balanced chromosomal rearrangements [64]. Moreover, different ranges of CNV size are typically captured by array-based and NGS-based methods. Although WGS may capture the whole spectrum of CNVs (and other structural variations), costs and large amounts of data requiring analysis and interpretation currently limits its use $[65,66]$.

Currently, copy number variation is defined as a genomic segment of at least $50 \mathrm{bp}$ that differs in copy number based on two or more genome comparisons (the smaller elements are known as insertions or deletions, indels) [65]. Copy number variation of human genome is even more extensive than single-nucleotide variation (a median of $8.9 \mathrm{Mb}$ of sequence is affected by structural variants in comparison to $3.6 \mathrm{Mb}$ of single-nucleotide polymorphisms [67]). As of 2014, the most extensive general population of $\mathrm{CNV}$ database of genomic variants (DGV) contains more than 2.3 million variants [68], and the bulk of structural variations identified in population controls are low-frequency variants (e.g., $65 \%$ of variants detected in 2504 individuals had VAF $<0.2 \%$ [67]). Together with a limited knowledge on human pathological copy number variation and functional importance of these genome elements, it creates huge challenges in $\mathrm{CNV}$ data interpretation $[69,70]$. Although the American College of Medical Genetics and Genomics provides some guidelines in $\mathrm{CNV}$ analysis [70], interpretation and reporting, multiple various workflows, and strategies exist $[60,69,71]$, and diagnostic outputs may substantially differ even in the same cohort of patients investigated by the same professionals over just several years [72]. Currently, the most extensively investigated are heterozygous de novo or inherited dominant CNVs. However, autosomal recessive, imprinting, and X-linked disorders (as much as 10\% of all identified causative CNVs in ID were X-linked in a study by Hehir-Kwa et al.) may also be uncovered [69, 73]. Although the pathogenic potential of $1-500 \mathrm{~kb}$ small CNVs has not been well elucidated and may not be reported in some laboratories performing aCGH (2010 consensus statement on diagnostic chromosomal microarray testing recommends a resolution of $\geq 400 \mathrm{~kb}$ as a balance of analytical and clinical sensitivity), small CNVs may account for a neurodevelopmental disease phenotype in at least $2 \%$ of patients, and this range of CNVs is of increasing importance due to spreading NGS-based CNV calling methods [74]. Although noncoding copy number variation is usually discarded as nonrelevant or uninterpretable, intergenic or intronic structural variation may affect gene regulation through position effect and disturbance of regulatory sequences or normal chromatin folding [75]. Moreover, somatically acquired structural variation may also play a role [76].

Since 2009, importance of CNVs in various epilepsy phenotypes has been shown in multiple studies. The biggest diagnostic yields have been achieved in patients with epilepsy and various brain malformations: pathogenic and likely pathogenic CNVs had $23.7 \%$ of 76 patients [77] and $22.5 \%$ of 169 patients [78]. Microarray testing has been informative in 3.4-8\% of patients with epileptic encephalopathy [79, 80], 10.9\% in 247 cases with epilepsy and associated ID/DD and/or CM [81], and 5\% in 805 patients with unselected epilepsy phenotypes [82]. Both recurrent $\mathrm{CNVs}$ at $15 \mathrm{q} 13.3,15 \mathrm{q} 11.2,16 \mathrm{p} 11.2$, and $16 \mathrm{p} 13.11$ and rare $\mathrm{CNV}$ s may play a significant role as one of the major risk factors for common epilepsies, including genetic generalized epilepsy [83, 84], absence epilepsies [85, 86], and Rolandic epilepsy [87]; however, lack of knowledge on the whole phenotypic expression and penetrance of these CNVs present considerable challenges for genetic counseling. 


\subsection{Next-generation sequencing testing in epilepsies: current problems and limitations}

There are two main groups of limitations and problems that must be taken into consideration while applying NGS technologies in a diagnostic testing: technological problems/limitations and psychosocial/bioethical implications (discussed in Section 2.7).

Although WGS interrogates almost the whole genome and WES-a coding part of the genome-diagnostic rate of WGS in patients with epilepsy and other phenotypically and genetically diverse neurodevelopmental disorders is seldom above $70 \%$, while the rate of WES usually does not exceed 50\%. Some types of mutations are reluctant to WGS (e.g., epigenetic mutations, structural chromosome rearrangements, tissue-restricted somatic mosaicism). Although our knowledge of WGS-reluctant human molecular pathology is very limited, there are several recent examples of such pathology discovered in patients with epilepsy. Postzygotic tissue-restricted somatic de novo mutations in AKT3, MTOR, and PIK3CA have been identified as the cause of cortical malformation syndromes associated with severe epilepsy [88], and somatic mutations in DCX, LIS1, FLNA, and TUBB2B genes as the cause of double cortex syndrome, periventricular nodular heterotopia, and pachygyria [89]. Recently found biallelic mutations in the box C/D snoRNA U8 gene SNORD118 as a cause of the cerebral microangiopathy leukoencephalopathy with calcifications and cysts are an example of a pathogenic genomic variation, not amenable to current WES variant filtering practices restricted to coding regions and canonical splice sites [90].

Deep intronic, intergenic, regulatory sequence variants (noncoding parts of genome), tandem repeats, mtDNA variants, CNVs, variants in GC-rich, repetitive, and homologous regions of exome may not be detected in WES [91]. However, at least some of the technological limitations of WES technologies may be solved. Capturing of mtDNA variation (e.g., by using MitoSeek tool; [92]) and CNV variant calling (see Section 2.5) may be incorporated into the method and WES data analysis pipeline. Although detection of very large or small (one to two exons) deletions may be limited, sensitivity of identifying CNVs containing three or more exons has been estimated to be $76 \%$, with a specificity of $94 \%$ [61]. As both CNVs and mtDNA variations [93] play a substantial role in the etiology of genetic epilepsies, these amendments are crucially important in this patient group. Unequal coverage of exome leading to missed variants (mostly in GC-rich, repetitive, and homologous regions) is a well-known problem [31, 91]. Therefore, when testing a limited number of genes in disorders with a limited genetic heterogeneity ( 50-300 genes comprising about $0.5-2 \mathrm{Mb}$ ), gene panels, possibly supplemented with Sanger sequencing for poorly covered sequences, may be a better approach [29]. However, as it was recently shown in a retrospective study, 99.7\% (1491/1533) of variants detected in gene panel testing had sufficient coverage for detection in WES [94]. Therefore, for disorders with extensive genetic and phenotypic heterogeneity, the minimal false-negative rate due to unequal coverage may be outweighed by a substantially larger diagnostic yield of WES due to a comprehensive nature of this technology. Sanger sequencing of potentially causative variants is also currently used for the confirmation of NGS testing. However, as it was shown by several groups, high-quality ( $\geq 500 \mathrm{Q}$ ) NGS variants do not require Sanger confirmation and restriction of Sanger confirmation to low-quality single-nucleotide variants, and all insertions/deletions $<10$ bp may reduce Sanger confirmation workload by $70-80 \%$ and enable cost savings [95]. 
Finally, the biggest part of false negatives in WES may be accounted for current variant filtration, annotation, and interpretation practices; therefore, rate of false negatives have a potential to diminish with accumulating information and bioinformatic/technological improvements $[96,97]$. Although too stringent criteria can lead to false negatives, most likely they are unavoidable in a current setting of clinical practice. False-positive diagnoses can potentially have more devastating consequences for the family (e.g., through erroneous application of prenatal testing); therefore, all doubtful variants are usually ascribed to variants of unknown significance (VUS): it is easier to specify earlier suspected diagnosis than to refute previously established diagnosis [24].

There are some other non-laboratory-dependent problems potentially leading to missed or misinterpreted variants. One of the major steps in variant annotation process is assessing variant frequency in the general population. However, population databases cannot be assumed as containing data of healthy people only [24]. Besides, the prevalence of reported severe diseasecausing variants in population controls points of the fact that incomplete penetrance and wider than appreciated expressivity are more inherent to genetic pathology than usually appreciated. One more problem potentially leading to a wrongful diagnosis is an erroneous annotation of variants and genes in databases and published data. Recently, several genes including $C A C N A 1 H$, $S C N 9 A, E F H C 1, C L C N 2, G A B R D$, and SPRX2, at first ascribed to various monogenic forms of epilepsy, have later been refuted as causative [9]. Finally, lots of very rare pathogenic variants are currently hiding in "private" databases of various laboratories. As both normal and pathogenic variation of human genome is almost endless (see Section 2.3), very large collaborative efforts for sharing both phenotypic and genotypic data of patients must be employed for the elucidation of these ultrarare variants and for ascribing them to certain phenotypes. Recently, the Epilepsy Genetics Initiative has created a database to house the clinically sequenced exomes (and, in due course, sequenced genomes) and phenotypic data of individuals with epilepsy; one unique purpose of which is to allow ongoing iterative reassessment of unsolved cases [49].

\subsection{Building new healthcare practices in a responsible way}

Incidental findings are not a new issue in clinical practice, for example, unanticipated findings in radiological imaging or even surgery, sometimes leading to dramatic changes in patient care, are well-known examples. However, all-inclusive nature of genomic testing, especially WES and WGS, means that the generation of a certain amount of unanticipated or incidental findings is unavoidable, currently confronted in $1-8 \%$ of all tested individuals [98]. Incidental findings in genetic testing have several definitions including more general "unexpected positive findings" [98] and deliberate search for pathogenic variants not related to the primary diagnostic question [99]. Some of these findings are "actionable," that is, measures may be implemented for preventing/alleviating the consequences of imminent genetic disorder. In other cases, no such measures exist. In any case, many psychosocial/bioethical issues may arise; therefore, all the main professional genetic organizations, including ESHG, ACMG, and CCMG, provide perspectives on how to handle unsolicited/incidental/secondary findings [23, 25, 98, 100].

Uncertainty of medical information, including pathogenicity assessments of laboratory or instrumental investigation results and prognostication, is also not a new issue in medicine. In genomic testing, a significant number of variants of unknown clinical significance (VUS) that 
cannot reliably be ascribed to either benign or pathogenic are generated. It is presumable that over time due to accumulating knowledge of benign and pathogenic human genome variation a considerable proportion of these VUS will receive their proper meaning. However, as a normal mutation rate will continue to generate a nearly infinite spectrum of variants, the challenge of VUS is going to persist; therefore, in clinical genetic practice, professionals must prepare their patients for the possibility of uncertainty due to VUS [23].

\subsection{Clinical utility of genetic and genomic testing in epilepsies}

Establishment of exact etiological diagnosis, where it is possible, is a standard of care in nowadays clinical practice. Precise genetic diagnosis has a huge impact on the individuals tested, their families, and community, as it allows timely medical interventions, informed reproductive choices, and avoidance of additional testing. In some cases it enables avoidance of inappropriate or detrimental treatments as illustrated by epilepsy due to POLG1 gene mutations where valproates are contraindicated due to a threat of fatal hepatic failure [101]. Precise diagnosis can also determine the eligibility for clinical trials or enable engagement into appropriate patient support groups [102]. Psychosocial benefits of ending the diagnostic odyssey may also be substantial [103]. Finally, accurate prognostic information can be used by families for obtaining appropriate social and educational services and making personal and financial plans.

Undoubtedly, the most important benefits that may be enabled by exact genetic diagnosis are disease course-changing specific treatments. With timely diagnosis, there is an opportunity to provide life-saving and disability-preventing specific treatments to some epilepsy patients. Specific therapies have been initiated or adjusted in $6-8 \%$ of diagnosed patients in some studies $[19,22]$. A significant group of treatable metabolic epilepsies provide one of the most veritable examples of precision medicine applications (see Section 2.4). Recent examples of specific treatments also include individuals with KCNT1 mutations treated with quinidine, children with KCNQ2 mutations treated with ezogabine (retigabine), individuals with GRIN2A mutations treated with memantine, and patients with mTORopathies treated with everolimus [49]. Fueled by novel epilepsy of genetic discoveries leading to further elucidation of pathogenetic disease mechanisms, the list of precision medicine applications in monogenic epilepsies will likely expand in the future. However, the first prerequisite to specific treatment applications in all these cases is an exact genetic diagnosis. Moreover, as currently up to one-third of all epilepsy cases are refractory to current treatments, new discoveries in monogenic forms of epilepsy may also fuel research and novel treatment target discoveries in common epilepsies.

In reaching diagnosis, comprehensiveness and untargeted approach of NGS technologies, especially WES, may be of special importance. It allows for elucidation of diagnoses in atypical, unusual, and not-full-blown (e.g., in young patients) phenotypes where phenotype-driven diagnostic hypothesis and targeted testing are impossible [19, 104]. Indeed, compatibility of a phenotype to that described in literature (the "first case bias") is one of the main factors in diagnostic hypothesis both raising and ascribing of pathogenicity to a novel variant. However, as of February 2015, 706 genes or $\sim 24 \%$ of all genes associated with a Mendelian phenotype in OMIM database were responsible for at least two "clinically discrete" phenotypes [33]. Comprehensiveness of WES is also important for diagnostics of more than one genetic disease in a patient; such cases comprised four of 105 diagnosed patients in a study by Sawyer et al. [22] 
and $4.6 \%$ of patients in a study by Yang et al. [105]. NGS testing may be the only opportunity for diagnosis in life-limiting disorders or in postmortem setting when DNA samples can be limited [41]. Finally, novel disease genes are also not an unusual finding in a clinical practice with WES or WGS testing and were found in 3.3-8.1\% of patients in various studies [37, 40, $102,104]$ and $23 \%$ of patients in FORGE study [22]. Importantly, each successful discovery opens horizons for diagnostic, preventive, and therapeutic opportunities for the corresponding disease [33]. The most common reasons for patients not to receive a diagnosis prior to WES in FORGE study were a significant genetic heterogeneity of the interrogated disorder, atypical presentation, missed diagnosis by other methods, and novel and ultrarare disorders [22].

\subsection{The role of a clinical geneticist}

Given all the complexities of genetic diseases' clinical presentation and phenotype evaluation, choice of the right genetic testing strategies, interpretation of genetic testing results and their communication to patients and families, genetic counseling regarding further risks and possibilities for prenatal diagnostics, and finally, sensitive and respectful consideration of all the psychosocial/bioethical aspects related to genetic diseases and genetic/genomic testing, the role of a clinical geneticist in the whole pathway of genetic diagnostics of a patient with epilepsy or seizures is undisputed. In the contemporary clinical genetic practice, geneticists must possess not only proper clinical skills but also abilities to use a vast range of bioinformatic tools and databases and have a deep knowledge of not only clinical genetics but also multiple genetic and genomic testing specificities.

Success of both targeted genetic testing and untargeted NGS approach is crucially dependent on the completeness and accuracy of phenotype evaluation [24, 26, 106]. Given the vast phenotypic variability of human monogenic and chromosomal disorders involving epilepsy or seizures, illustrated by EpiGene database (http://www.kimg.eu/en/tools/epigene-database), phenotyping of patient may include not only neurological examinations and tests but also thorough assessment of dysmorphic features, cutaneous signs, congenital malformations, variable symptoms of any other organ or organ system impairment, results of prior laboratory/radiological and other testings, information on cognitive functioning, etc. Family history/ genealogy data may be helpful. Contrary to expectations of some people, with the advent of NGS testing, importance of thorough phenotyping did not diminish [106]. On the contrary, the final stages of variant annotation (gene level) and accurate variant interpretation are crucially dependent on the full phenotypic picture of a patient. Besides, as in many cases, phenotype-driven diagnostic hypothesis is not raised; a constant contact between laboratory and clinics with possibilities to perform a "reverse phenotyping" or "genotype to phenotype" correlation of identified variants is very important. Indeed, diagnostic yields were lower in studies where exome sequencing and interpretation of results were done in laboratories separate from clinical units (e.g., gene panel of 447 genes in 148 patients with a suspicion of mitochondrial diseases gave a diagnostic yield of only $9.4 \%$ in a separate laboratory [107] in comparison to $39 \%$ yield in a group of 109 patients tested with a gene panel of 238 genes in a laboratory connected to clinical unit [55]). In a recently published study, discordance rate in the initial interpretation of causal variants between laboratory and clinical geneticists was approximately $10 \%$ [108]. Finally, standardization and automation of phenotyping may be facilitated by tools like PhenoTips [109]. 


\section{Diagnostic testing in epilepsy genetic clinical practice: proposed workflow}

Currently, there are no recommendations or guidelines for genetic testing in epilepsy patients addressing specificities of NGS technologies [28]. We propose a simplified diagnostic workflow based on expected diagnostic yields and cost-effectiveness in various clinical situations encountered in epilepsy genetic clinical practice (Figure 1). The choice of a diagnostic route that is the most appropriate in a given clinical situation requires not only deep knowledge of

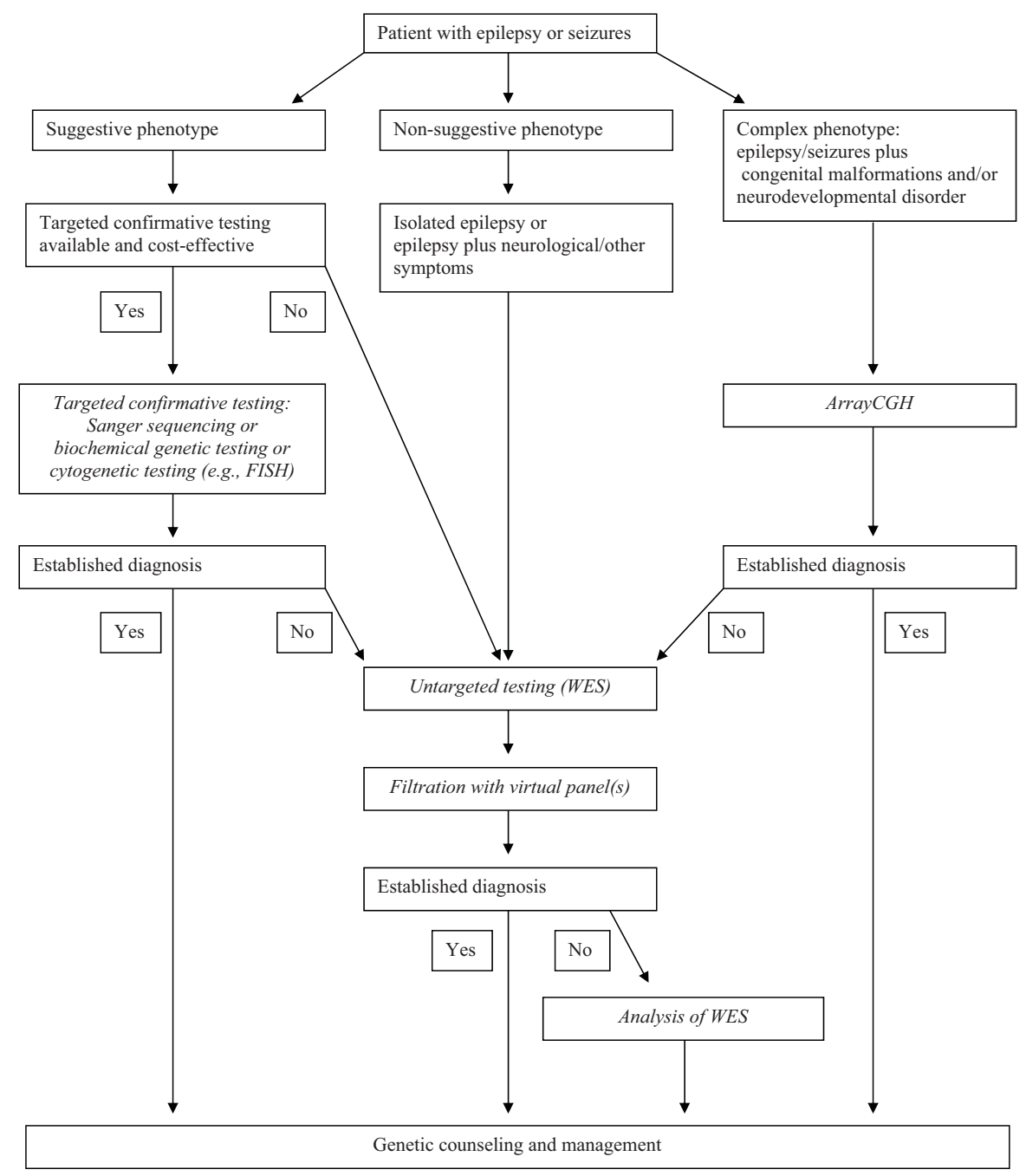

Figure 1. Provisional diagnostic workflow in patients with epilepsy or seizures. 
a genetic architecture and a molecular pathology of a disorder; multiple technical specificities and limitations/disadvantages of diagnostic methods must be taken into consideration.

\section{Author details}

Birute Tumiene $^{1 *}$, Algirdas Utkus ${ }^{1}$, Vaidutis Kučinskas ${ }^{2}$, Aleš Maver ${ }^{3}$ and Borut Peterlin ${ }^{3}$

*Address all correspondence to: birute.tumiene@santa.lt

1 Department of Human and Medical Genetics, Centre for Medical Genetics, Vilnius University, Vilnius, Lithuania

2 Department of Human and Medical Genetics, Centre for Human Genomics, Vilnius University, Vilnius, Lithuania

3 Clinical Institute for Medical Genetics, Division of Gynecology, University of Ljubljana Medical Centre, Ljubljana, Slovenia

\section{References}

[1] Peljto AL, Barker-Cummings C, Vasoli VM, Leibson CL, Hauser WA, Buchhalter JR, Ottman R. Familial risk of epilepsy: A population-based study. Brain. 2014 Mar;137(Pt 3):795-805. DOI: 10.1093/brain/awt368

[2] Speed D, O'Brien TJ, Palotie A, Shkura K, Marson AG, Balding DJ, Johnson MR. Describing the genetic architecture of epilepsy through heritability analysis. Brain. 2014 Oct;137(Pt 10):2680-2689. DOI: 10.1093/brain/awu206

[3] Pal DK, Pong AW, Chung WK. Genetic evaluation and counseling for epilepsy. Nature Reviews Neurology. 2010 Aug;6(8):445-453. DOI: 10.1038/nrneurol.2010.92

[4] Kliegman RM, Bordini BJ, Basel D, Nocton JJ. How doctors think: Common diagnostic errors in clinical judgment-lessons from an undiagnosed and rare disease program. Pediatrics Clinics of North America. 2017 Feb;64(1):1-15. DOI: 10.1016/j.pcl.2016.08.002

[5] Sisodiya SM. Genetic screening and diagnosis in epilepsy? Current Opinion in Neurology. 2015 Apr;28(2):136-142. DOI: 10.1097/WCO.0000000000000180

[6] van Bokhoven H. Genetic and epigenetic networks in intellectual disabilities. Annual Review of Genetics. 2011;45:81-104. DOI: 10.1146/annurev-genet-110410-132512

[7] Greenberg DA, Subaran R. Blinders, phenotype, and fashionable genetic analysis: A critical examination of the current state of epilepsy genetic studies. Epilepsia. 2011 Jan;52(1):1-9. DOI: 10.1111/j.1528-1167.2010.02734.x

[8] Beck C, Moulard B, Steinlein O, Guipponi M, Vallee L, Montpied P, et al. A nonsense mutation in the alpha4 subunit of the nicotinic acetylcholine receptor (CHRNA4) cosegregates with 20q-linked benign neonatal familial convulsions (EBNI). Neurobiology of Disease. 1994 Nov;1(1-2):95-99 
[9] Helbig I, Tayoun AA. Understanding genotypes and phenotypes in epileptic encephalopathies. Molecular Syndromology. 2016 Sep;7(4):172-181

[10] Malek N, Stewart W, Greene J. The progressive myoclonic epilepsies. Practical Neurology. 2015 Jun;15(3):164-171. DOI: 10.1136/practneurol-2014-000994

[11] Busch RM, Najm I, Hermann BP, Eng C. Genetics of cognition in epilepsy. Epilepsy Behaviour. 2014 Dec;41:297-306. DOI: 10.1016/j.yebeh.2014.05.026

[12] Guerrini R, Dobyns WB. Malformations of cortical development: Clinical features and genetic causes. Lancet Neurology. 2014 Jul;13(7):710-726. DOI: 10.1016/S1474-4422(14) 70040-7

[13] Longo MG, Vairo F, Souza CF, Giugliani R, Vedolin LM. Brain imaging and genetic risk in the pediatric population, part 1: Inherited metabolic diseases. Neuroimaging Clinics of North America. 2015 Feb;25(1):31-51. DOI: 10.1016/j.nic.2014.09.004

[14] Longo MG, Félix TM, Ashton-Prolla P, Vedolin LM. Brain imaging and genetic risk in the pediatric population, part 2: Congenital malformations of the central nervous system. Neuroimaging Clinics of North America. 2015 Feb;25(1):53-67. DOI: 10.1016/j. nic.2014.09.003

[15] Patel J, Mercimek-Mahmutoglu S. Epileptic encephalopathy in childhood: A stepwise approach for identification of underlying genetic causes. Indian Journal of Pediatrics. 2016 Oct;83(10):1164-1174. DOI: 10.1007/s12098-015-1979-9

[16] Weiss MM, Van der Zwaag B, Jongbloed JD, Vogel MJ, Brüggenwirth HT, Lekanne Deprez $\mathrm{RH}$, et al. Best practice guidelines for the use of next-generation sequencing applications in genome diagnostics: A national collaborative study of Dutch genome diagnostic laboratories. Human Mutation. 2013 Oct;34(10):1313-1321. DOI: 10.1002/ humu.22368

[17] Mercimek-Mahmutoglu S, Patel J, Cordeiro D, Hewson S, Callen D, Donner EJ, et al. Diagnostic yield of genetic testing in epileptic encephalopathy in childhood. Epilepsia. 2015 May;56(5):707-716. DOI: 10.1111/epi.12954

[18] López-Pisón J, García-Jiménez MC, Monge-Galindo L, Lafuente-Hidalgo M, PérezDelgado R, García-Oguiza A, Peña-Segura JL. Our experience with the aetiological diagnosis of global developmental delay and intellectual disability: 2006-2010. Neurologia. 2014 Sep;29(7):402-407. DOI: 10.1016/j.nrl.2013.10.006

[19] Soden SE, Saunders CJ, Willig LK, Farrow EG, Smith LD, Petrikin JE, et al. Effectiveness of exome and genome sequencing guided by acuity of illness for diagnosis of neurodevelopmental disorders. Science Translational Medicine. 2014 Dec 3;6(265):265ra168. DOI: 10.1126/scitranslmed.3010076

[20] Monroe GR, Frederix GW, Savelberg SM, de Vries TI, Duran KJ, van der Smagt JJ, et al. Effectiveness of whole-exome sequencing and costs of the traditional diagnostic trajectory in children with intellectual disability. Genetics in Medicine. 2016 Sep;18(9):949-956. DOI: 10.1038/gim.2015.200 
[21] Stark Z, Schofield D, Alam K, Wilson W, Mupfeki N, Macciocca I, et al. Prospective comparison of the cost-effectiveness of clinical whole-exome sequencing with that of usual care overwhelmingly supports early use and reimbursement. Genetics in Medicine. 2017 Jan 26. DOI: 10.1038/gim.2016.221

[22] Sawyer SL, Hartley T, Dyment DA, Beaulieu CL, Schwartzentruber J, Smith A, et al. Utility of whole-exome sequencing for those near the end of the diagnostic odyssey: Time to address gaps in care. Clinical Genetics. 2016 Mar;89(3):275-284. DOI: 10.1111/ cge. 12654

[23] van El CG, Cornel MC, Borry P, Hastings RJ, Fellmann F, Hodgson SV, et al. Wholegenome sequencing in health care. Recommendations of the European society of human genetics. European Journal of Human Genetics. 2013 Jun;21(Suppl 1):S1-S5

[24] Richards S, Aziz N, Bale S, Bick D, Das S, Gastier-Foster J, et al. Standards and guidelines for the interpretation of sequence variants: A joint consensus recommendation of the American College of Medical Genetics and Genomics and the Association for Molecular Pathology. Genetics in Medicine. 2015 May;17(5):405-424. DOI: 10.1038/gim.2015.30

[25] Boycott K, Hartley T, Adam S, Bernier F, Chong K, Fernandez BA, et al. The clinical application of genome-wide sequencing for monogenic diseases in Canada: Position statement of the Canadian College of Medical Geneticists. Journal of Medical Genetics. 2015 Jul;52(7):431-437. DOI: 10.1136/jmedgenet-2015-103144

[26] Shashi V, McConkie-Rosell A, Rosell B, Schoch K, Vellore K, McDonald M, et al. The utility of the traditional medical genetics diagnostic evaluation in the context of nextgeneration sequencing for undiagnosed genetic disorders. Genetics in Medicine. 2014 Feb;16(2):176-182. DOI: 10.1038/gim.2013.99

[27] Trump N, McTague A, Brittain H, Papandreou A, Meyer E, Ngoh A, et al. Improving diagnosis and broadening the phenotypes in early-onset seizure and severe developmental delay disorders through gene panel analysis. Journal of Medical Genetics. 2016 May;53(5):310-317. DOI: 10.1136/jmedgenet-2015-103263

[28] Ottman R, Hirose S, Jain S, Lerche H, Lopes-Cendes I, Noebels JL, et al. Genetic testing in the epilepsies--report of the ILAE Genetics Commission. Epilepsia. 2010 Apr;51(4):655670. DOI: 10.1111/j.1528-1167.2009.02429.x

[29] Klein CJ, Foroud TM. Neurology individualized medicine: When to use next-generation sequencing panels. Mayo Clinic Proceedings. 2017 Feb;92(2):292-305. DOI: 10.1016/j. mayocp.2016.09.008

[30] Wright CF, Middleton A, Burton H, Cunningham F, Humphries SE, Hurst J, et al. Policy challenges of clinical genome sequencing. BMJ. 2013 Nov 22;347:f6845. DOI: 10.1136/ bmj.f6845

[31] Xue Y, Ankala A, Wilcox WR, Hegde MR. Solving the molecular diagnostic testing conundrum for Mendelian disorders in the era of next-generation sequencing: Single-gene, gene panel, or exome/genome sequencing. Genetics in Medicine. 2015 Jun;17(6):444-451. DOI: $10.1038 /$ gim.2014.122 
[32] Lek M, Karczewski KJ, Minikel EV, Samocha KE, Banks E, Fennell T, et al. Analysis of protein-coding genetic variation in 60,706 humans. Nature. 2016 Aug 18;536(7616):285291. DOI: $10.1038 /$ nature19057

[33] Chong JX, Buckingham KJ, Jhangiani SN, Boehm C, Sobreira N, Smith JD, et al. The genetic basis of Mendelian phenotypes: Discoveries, challenges, and opportunities. American Journal of Human Genetics. 2015 Aug 6;97(2):199-215. DOI: 10.1016/j.ajhg. 2015.06.009

[34] Martin HC, Kim GE, Pagnamenta AT, Murakami Y, Carvill GL, Meyer E, et al. Clinical whole-genome sequencing in severe early-onset epilepsy reveals new genes and improves molecular diagnosis. Human Molecular Genetics. 2014 Jun 15;23(12):32003211. DOI: $10.1093 / \mathrm{hmg} / \mathrm{ddu} 030$

[35] Gilissen C, Hehir-Kwa JY, Thung DT, van de Vorst M, van Bon BW, Willemsen MH, et al. Genome sequencing identifies major causes of severe intellectual disability. Nature. 2014 Jul 17;511(7509):344-347. DOI: 10.1038/nature13394

[36] Taylor JC, Martin HC, Lise S, Broxholme J, Cazier JB, Rimmer A, et al. Factors influencing success of clinical genome sequencing across a broad spectrum of disorders. Natural Genetics. 2015 Jul;47(7):717-726. DOI: 10.1038/ng.3304

[37] Helbig KL, Farwell Hagman KD, Shinde DN, Mroske C, Powis Z, Li S, et al. Diagnostic exome sequencing provides a molecular diagnosis for a significant proportion of patients with epilepsy. Genetics in Medicine. 2016 Sep;18(9):898-905. DOI: 10.1038/gim.2015.186

[38] Dimassi S, Labalme A, Ville D, Calender A, Mignot C, Boutry-Kryza N, et al. Wholeexome sequencing improves the diagnosis yield in sporadic infantile spasm syndrome. Clinical Genetics. 2016 Feb;89(2):198-204. DOI: 10.1111/cge.12636

[39] Srivastava S, Cohen JS, Vernon H, Barañano K, McClellan R, Jamal L, et al. Clinical whole exome sequencing in child neurology practice. Annals of Neurology. 2014 Oct;76(4):473483. DOI: 10.1002/ana.24251

[40] Farwell KD, Shahmirzadi L, El-Khechen D, Powis Z, Chao EC, Tippin Davis B, et al. Enhanced utility of family-centered diagnostic exome sequencing with inheritance model-based analysis: Results from 500 unselected families with undiagnosed genetic conditions. Genetics in Medicine. 2015 Jul;17(7):578-586. DOI: 10.1038/gim.2014.154

[41] Stark Z, Tan TY, Chong B, Brett GR, Yap P, Walsh M, et al. A prospective evaluation of whole-exome sequencing as a first-tier molecular test in infants with suspected monogenic disorders. Genetics in Medicine. 2016 Nov;18(11):1090-1096. DOI: 10.1038/gim.2016.1

[42] Ales M, Luca L, Marija V, Gorazd R, Karin W, Ana B, et al. Phenotype-driven gene target definition in clinical genome-wide sequencing data interpretation. Genetics in Medicine. 2016 Nov;18(11):1102-1110. DOI: 10.1038/gim.2016.22

[43] Carvill GL, Heavin SB, Yendle SC, McMahon JM, O'Roak BJ, Cook J, et al. Targeted resequencing in epileptic encephalopathies identifies denovo mutations in CHD2 and SYNGAP1. Nature Genetics. 2013 Jul;45(7):825-830. DOI: 10.1038/ng.2646 
[44] Parrini E, Marini C, Mei D, Galuppi A, Cellini E, Pucatti D, et al. Diagnostic targeted resequencing in 349 patients with drug-resistant pediatric epilepsies identifies causative mutations in 30 different genes. Human Mutation. 2017 Feb;38(2):216-225. DOI: 10.1002/ humu.23149

[45] Møller RS, Larsen LH, Johannesen KM, Talvik I, Talvik T, Vaher U, et al. Gene panel testing in epileptic encephalopathies and familial epilepsies. Molecular Syndromology. 2016 Sep;7(4):210-219

[46] Wang Y, Du X, Bin R, Yu S, Xia Z, Zheng G, et al. Genetic variants identified from epilepsy of unknown etiology in Chinese children by targeted exome sequencing. Scientific Reports. 2017 Jan 11;7:40319. DOI: 10.1038/srep40319

[47] Chambers C, Jansen LA, Dhamija R. Review of commercially available epilepsy genetic panels. Journal of Genetic Counseling. 2016 Apr;25(2):213-217. DOI: 10.1007/ s10897-015-9906-9

[48] Pearl PL. Amenable treatable severe pediatric epilepsies. Seminars in Pediatrics Neurology. 2016 May;23(2):158-166. DOI: 10.1016/j.spen.2016.06.004

[49] EpiPM Consortium. A roadmap for precision medicine in the epilepsies. Lancet Neurology. 2015 Dec;14(12):1219-1228. DOI: 10.1016/S1474-4422(15)00199-4

[50] Oz G, Alger JR, Barker PB, Bartha R, Bizzi A, Boesch C, et al. Clinical proton MR spectroscopy in central nervous system disorders. Radiology. 2014 Mar;270(3):658-679. DOI: 10.1148/radiol.13130531

[51] Ibrahim M, Parmar HA, Hoefling N, Srinivasan A. Inborn errors of metabolism: combining clinical and radiologic clues to solve the mystery. AJR American Journal of Roentgenology. 2014 Sep;203(3):W315-W327. DOI: 10.2214/AJR.13.11154

[52] Dulac O, Plecko B, Gataullina S, Wolf NI. Occasional seizures, epilepsy, and inborn errors of metabolism. Lancet Neurology. 2014 Jul;13(7):727-739. DOI: 10.1016/S1474-4422 (14)70110-3

[53] Kölker S, Garcia-Cazorla A, Valayannopoulos V, Lund AM, Burlina AB, Sykut-Cegielska $\mathrm{J}$, et al. The phenotypic spectrum of organic acidurias and urea cycle disorders. Part 1 : The initial presentation. Journal of Inherited Metabolic Disease. 2015 Nov;38(6):10411057. DOI: 10.1007/s10545-015-9839-3

[54] Lemke JR, Riesch E, Scheurenbrand T, Schubach M, Wilhelm C, Steiner I, et al. Targeted next generation sequencing as a diagnostic tool in epileptic disorders. Epilepsia. 2012 Aug;53(8):1387-1398. DOI: 10.1111/j.1528-1167.2012.03516.x

[55] Wortmann SB, Koolen DA, Smeitink JA, van den Heuvel L, Rodenburg RJ. Whole exome sequencing of suspected mitochondrial patients in clinical practice. Journal of Inherited Metabolic Disease. 2015 May;38(3):437-443. DOI: 10.1007/s10545-015-9823-y

[56] Zuberi SM. Chromosome disorders associated with epilepsy. Handbook of Clinical Neurology. 2013;111:543-548. DOI: 10.1016/B978-0-444-52891-9.00057-9 
[57] Miller DT, Adam MP, Aradhya S, Biesecker LG, Brothman AR, Carter NP, et al. Consensus statement: Chromosomal microarray is a first-tier clinical diagnostic test for individuals with developmental disabilities or congenital anomalies. American Journal of Human Genetics. 2010 May 14;86(5):749-764. DOI: 10.1016/j.ajhg.2010.04.006

[58] Charalsawadi C, Khayman J, Praphanphoj V, Limprasert P. Screening for subtelomeric rearrangements in Thai patients with intellectual disabilities using FISH and review of literature on subtelomeric FISH in 15,591 cases with intellectual disabilities. Genetic Reseach International. 2016;2016:9153740

[59] Koolen DA, Nillesen WM, Versteeg MH, Merkx GF, Knoers NV, Kets M, et al. Screening for subtelomeric rearrangements in 210 patients with unexplained mental retardation using multiplex ligation dependent probe amplification (MLPA). Journal of Medical Genetics. 2004 Dec;41(12):892-899

[60] Hanemaaijer NM, Sikkema-Raddatz B, van der Vries G, Dijkhuizen T, Hordijk R, van Essen AJ, et al. Practical guidelines for interpreting copy number gains detected by high-resolution array in routine diagnostics. European Journal of Human Genetics. 2012 Feb;20(2):161-165. DOI: 10.1038/ejhg.2011.174

[61] Krumm N, Sudmant PH, Ko A, O'Roak BJ, Malig M, Coe BP, et al. Copy number variation detection and genotyping from exome sequence data. Genome Research. 2012 Aug;22(8):1525-1532. DOI: 10.1101/gr.138115.112

[62] Zollino M, Ponzi E, Gobbi G, Neri G. The ring 14 syndrome. European Journal of Medical Genetics. 2012 May;55(5):374-380. DOI: 10.1016/j.ejmg.2012.03.009

[63] Daber RD, Conlin LK, Leonard LD, Canevini MP, Vignoli A, Hosain S, et al. Ring chromosome 20. European Journal of Medical Genetics. 2012 May;55(5):381-387. DOI: 10.1016/j.ejmg.2012.02.004

[64] Hochstenbach R, van Binsbergen E, Engelen J, Nieuwint A, Polstra A, Poddighe P, et al. Array analysis and karyotyping: Workflow consequences based on a retrospective study of 36,325patients with idiopathic developmental delay in the Netherlands. European Journal of Medical Genetics. 2009 Jul-Aug;52(4):161-169. DOI: 10.1016/j.ejmg.2009.03.015

[65] Zarrei M, MacDonald JR, Merico D, Scherer SW. A copy number variation map of the human genome. Nature Reviews Genetics. 2015 Mar;16(3):172-183. DOI: 10.1038/nrg3871

[66] Ruderfer DM, Hamamsy T, Lek M, Karczewski KJ, Kavanagh D, Samocha KE, et al. Patterns of genic intolerance of rare copy number variation in 59,898 human exomes. Nature Genetics. 2016 Oct;48(10):1107-1111. DOI: 10.1038/ng.3638

[67] Sudmant PH, Rausch T, Gardner EJ, Handsaker RE, Abyzov A, Huddleston J, et al. An integrated map of structural variation in 2,504 human genomes. Nature. 2015 Oct 1;526(7571):75-81. DOI: 10.1038/nature15394

[68] MacDonald JR, Ziman R, Yuen RK, Feuk L, Scherer SW. The database of genomic variants: A curated collection of structural variation in the human genome. Nucleic Acids Researcch. 2014 Jan;42(Database issue):D986-D992. DOI: 10.1093/nar/gkt958 
[69] Hehir-Kwa JY, Pfundt R, Veltman JA, de Leeuw N. Pathogenic or not? Assessing the clinical relevance of copy number variants. Clinical Genetics. 2013 Nov;84(5):415-421. DOI: $10.1111 /$ cge.12242

[70] Kearney HM, Thorland EC, Brown KK, Quintero-Rivera F, South ST, Working Group of the American College of Medical Genetics Laboratory Quality Assurance Committee. American College of Medical Genetics standards and guidelines for interpretation and reporting of postnatal constitutional copy number variants. Genetics in Medicine. 2011 Jul;13(7):680-685. DOI: 10.1097/GIM.0b013e3182217a3a

[71] Carreira IM, Ferreira SI, Matoso E, Pires LM, Ferrão J, Jardim A, et al. Copy number variants prioritization after array-CGH analysis - a cohort of 1000 patients. Molecular Cytogenetics. 2015 Dec 30;8:103. DOI: 10.1186/s13039-015-0202-z

[72] Palmer E, Speirs H, Taylor PJ, Mullan G, Turner G, Einfeld S, et al. Changing interpretation of chromosomal microarray over time in a community cohort with intellectual disability. American Journal of Medical Genetics A. 2014 Feb;164A(2):377-385. DOI: 10.1002/ajmg.a.36279

[73] Paciorkowski AR, Keppler-Noreuil K, Robinson L, Sullivan C, Sajan S, Christian SL, et al. Deletion 16p13.11 uncovers NDE1 mutations on the non-deleted homolog and extends the spectrum of severe microcephaly to include fetal brain disruption. American Journal of Medical Genetics A. 2013 Jul;161A(7):1523-1530. DOI: 10.1002/ajmg.a.35969

[74] Asadollahi R, Oneda B, Joset P, Azzarello-Burri S, Bartholdi D, Steindl K, et al. The clinical significance of small copy number variants in neurodevelopmental disorders. Journal of Medical Genetics. 2014 Oct;51(10):677-688. DOI: 10.1136/jmedgenet-2014-102588

[75] Spielmann M, Mundlos S. Looking beyond the genes: The role of non-coding variants in human disease. Human Molecular Genetics. 2016 Oct 1;25(R2):R157-R165

[76] Magaard Koldby K, Nygaard M, Christensen K, Christiansen L. Somatically acquired structural genetic differences: A longitudinal study of elderly Danish twins. European Journla of Human Genetics. 2016 Oct;24(10):1506-1510. DOI: 10.1038/ejhg.2016.34

[77] Wincent J, Kolbjer S, Martin D, Luthman A, Åmark P, Dahlin M, Anderlid BM. Copy number variations in children with brain malformations and refractory epilepsy. American Journal of Human Genetics. 2015 Mar;167A(3):512-523. DOI: 10.1002/ajmg.a.36886

[78] Kariminejad R, Lind-Thomsen A, Tümer Z, Erdogan F, Ropers HH, Tommerup N, et al. High frequency of rare copy number variants affecting functionally related genes in patients with structural brain malformations. Human Mutation. 2011 Dec;32(12):14271435. DOI: 10.1002/humu.21585

[79] Mefford HC, Yendle SC, Hsu C, Cook J, Geraghty E, McMahon JM, et al. Rare copy number variants are an important cause of epileptic encephalopathies. Annals of Neurology. 2011 Dec;70(6):974-985. DOI: 10.1002/ana.22645

[80] Ma Y, Chen C, Wang Y, Wu L, He F, Chen C, et al. Analysis copy number variation of Chinese children in early-onset epileptic encephalopathies with unknown cause. Clinical Genetics. 2016 Nov;90(5):428-436. DOI: 10.1111/cge.12768 
[81] Nicholl J, Waters W, Suwalski S, Brown S, Hull Y, Harbord MG, et al. Epilepsy with cognitive deficit and autism spectrum disorders: prospective diagnosis by array CGH. American Journal of Medical Genetics B Neuropsychiatry Genetics. 2013 Jan;162B(1):24-35. DOI: 10.1002/ajmg.b.32114

[82] Olson H, Shen Y, Avallone J, Sheidley BR, Pinsky R, Bergin AM, et al. Copy number variation plays an important role in clinical epilepsy. Annals of Neurology. 2014 Jun;75(6):943-958. DOI: 10.1002/ana.24178

[83] Mullen SA, Carvill GL, Bellows S, Bayly MA, Trucks H, Lal D, et al. Copy number variants are frequent in genetic generalized epilepsy with intellectual disability. Neurology. 2013 Oct 22;81(17):1507-1514. DOI: 10.1212/WNL.0b013e3182a95829

[84] Lal D, Ruppert AK, Trucks H, Schulz H, de Kovel CG, Kasteleijn-Nolst Trenité D, et al. Burden analysis of rare microdeletions suggests a strong impact of neurodevelopmental genes in genetic generalised epilepsies. PLoS Genetics. 2015 May 7;11(5):e1005226. DOI: 10.1371/journal.pgen.1005226

[85] Addis L, Rosch RE, Valentin A, Makoff A, Robinson R, Everett KV, Nashef L, Pal DK. Analysis of rare copy number variation in absence epilepsies. Neurology Genetics. 2016 Mar 22;2(2):e56. DOI: 10.1212/NXG.0000000000000056

[86] Depondt C. Copy number variants in absence epilepsy: Further complications of the picture. Neurology Genetics. 2016 Mar 22;2(2):e67. DOI: 10.1212/NXG.0000000000000067

[87] Reinthaler EM, Lal D, Lebon S, Hildebrand MS, Dahl HH, Regan BM, et al. 16p11.2 600 $\mathrm{kb}$ Duplications confer risk for typical and atypical Rolandic epilepsy. Human Molecular Genetics. 2014 Nov 15;23(22):6069-6080. DOI: 10.1093/hmg/ddu306

[88] Poduri A, Evrony GD, Cai X, Walsh CA. Somatic mutation, genomic variation, and neurological disease. Science. 2013 Jul 5;341(6141):1237758. DOI: 10.1126/science.1237758

[89] Jamuar SS, Walsh CA. Somatic mutations in cerebral cortical malformations. New England Journal of Medicine. 2014 Nov 20;371(21):2038. DOI: 10.1056/NEJMc1411784

[90] Jenkinson EM, Rodero MP, Kasher PR, Uggenti C, Oojageer A, Goosey LC, et al. Mutations in SNORD118 cause the cerebral microangiopathy leukoencephalopathy with calcifications and cysts. Nature Genetics. 2016 Oct;48(10):1185-1192. DOI: 10.1038/ng.3661

[91] Sun Y, Ruivenkamp CA, Hoffer MJ, Vrijenhoek T, Kriek M, van Asperen CJ, et al. Nextgeneration diagnostics: gene panel, exome, or whole genome? Human Mutation. 2015 Jun;36(6):648-655. DOI: 10.1002/humu.22783

[92] Guo Y, Li J, Li CI, Shyr Y, Samuels DC. MitoSeek: Extracting mitochondria information and performing high-throughput mitochondria sequencing analysis. Bioinformatics. 2013 May 1;29(9):1210-1211. DOI: 10.1093/bioinformatics/btt118

[93] Finsterer J, Zarrouk MS. Epilepsy in mitochondrial disorders. Seizure. 2012 Jun;21(5):316321. DOI: $10.1016 /$ j.seizure.2012.03.003

[94] LaDuca H, Farwell KD, Vuong H, Lu HM, Mu W, Shahmirzadi L, et al. Exome sequencing covers $>98 \%$ of mutations identified on targeted next generation sequencing panels. PLoS One. 2017 Feb 2;12(2):e0170843. DOI: 10.1371/journal.pone.0170843 
[95] Strom SP, Lee H, Das K, Vilain E, Nelson SF, Grody WW, Deignan JL. Assessing the necessity of confirmatory testing for exome-sequencing results in a clinical molecular diagnostic laboratory. Genetics in Medicine. 2014 Jul;16(7):510-515. DOI: 10.1038/ gim.2013.183

[96] Shamseldin HE, Maddirevula S, Faqeih E, Ibrahim N, Hashem M, Shaheen R, Alkuraya FS. Increasing the sensitivity of clinical exome sequencing through improved filtration strategy. Genetics in Medicine. 2016 Oct 6. DOI: 10.1038/gim.2016.155

[97] Salgado D, Bellgard MI, Desvignes JP, Béroud C. How to identify pathogenic mutations among all those variations: Variant annotation and filtration in the genome sequencing era. Human Mutation. 2016 Dec;37(12):1272-1282. DOI: 10.1002/humu.23110

[98] Hehir-Kwa JY, Claustres M, Hastings RJ, van Ravenswaaij-Arts C, Christenhusz G, Genuardi M, et al. Towards a European consensus for reporting incidental findings during clinical NGS testing. European Journal of Human Genetics. 2015 Dec;23(12):16011606. DOI: 10.1038/ejhg.2015.111

[99] Green RC, Berg JS, Grody WW, Kalia SS, Korf BR, Martin CL, et al. ACMG recommendations for reporting of incidental findings in clinical exome and genome sequencing. Genetics in Medicine. 2013 Jul;15(7):565-574. DOI: 10.1038/gim.2013.73

[100] Kalia SS, Adelman K, Bale SJ, Chung WK, Eng C, Evans JP, et al. Recommendations for reporting of secondary findings in clinical exome and genome sequencing, 2016 update (ACMG SF v2.0): A policy statement of the American College of Medical Genetics and Genomics. Genetics in Medicine. 2017 Feb;19(2):249-255. DOI: 10.1038/gim.2016.190

[101] Hynynen J, Komulainen T, Tukiainen E, Nordin A, Arola J, Kälviäinen R, et al. Acute liver failure after valproate exposure in patients with POLG1 mutations and the prognosis after liver transplantation. Liver Transplantation. 2014 Nov;20(11):1402-1412. DOI: $10.1002 / 1 t .23965$

[102] Iglesias A, Anyane-Yeboa K, Wynn J, et al. The usefulness of whole-exome sequencing in routine clinical practice. Genetics in Medicine 2014;16(12):922-931

[103] Beaulieu CL, Majewski J, Schwartzentruber J, Samuels ME, Fernandez BA, Bernier FP, et al. FORGE Canada Consortium: Outcomes of a 2-year national rare-disease genediscovery project. American Journal of Human Genetics. 2014 Jun 5;94(6):809-817. DOI: 10.1016/j.ajhg.2014.05.003

[104] Zhu X, Petrovski S, Xie P, Ruzzo EK, Lu YF, McSweeney KM, et al. Whole-exome sequencing in undiagnosed genetic diseases: Interpreting 119 trios. Genetics in Medicine. 2015 Oct;17(10):774-81. DOI: 10.1038/gim.2014.191

[105] Yang Y, Muzny DM, Xia F, Niu Z, Person R, Ding Y, et al. Molecular findings among patients referred for clinical whole-exome sequencing. JAMA. 2014 Nov 12;312(18):18701879. DOI: 10.1001/jama.2014.14601

[106] Hennekam RC, Biesecker LG. Next-generation sequencing demands next-generation phenotyping. Human Mutation. 2012 May;33(5):884-886. DOI: 10.1002/humu.22048 
[107] DaRe JT, Vasta V, Penn J, Tran NT, Hahn SH. Targeted exome sequencing for mitochondrial disorders reveals high genetic heterogeneity. BMC Medical Genetics. 2013 Nov 11;14:118. DOI: 10.1186/1471-2350-14-118

[108] Shashi V, McConkie-Rosell A, Schoch K, Kasturi V, Rehder C, Jiang YH, et al. Practical considerations in the clinical application of whole-exome sequencing. Clinical Genetics. 2016 Feb;89(2):173-181. DOI: 10.1111/cge.12569

[109] Girdea M, Dumitriu S, Fiume M, Bowdin S, Boycott KM, Chénier S, et al. PhenoTips: Patient phenotyping software for clinical and research use. Human Mutation. 2013 Aug;34(8):1057-1065. DOI: 10.1002/humu.22347

[110] Leu C, Coppola A, Sisodiya SM. Progress from genome-wide association studies and copy number variant studies in epilepsy. Current Opinion in Neurology. 2016 Apr;29(2):158-167. DOI: 10.1097/WCO.0000000000000296

[111] Nevado J, Mergener R, Palomares-Bralo M, Souza KR, Vallespín E, Mena R, et al. New microdeletion and microduplication syndromes: A comprehensive review. Genetics in Molecular Biology. 2014 Mar;37(1 Suppl):210-219 
